\title{
Dietary fish oil supplements depress milk fat yield and alter milk fatty acid composition in lactating cows fed grass silage-based diets
}

\author{
P. Kairenius, ${ }^{*}$ A. Ärölä, ${ }^{*}$ H. Leskinen, ${ }^{*}$ V. Toivonen, ${ }^{*}$ S. Ahvenjärvi, ${ }^{*}$ A. Vanhatalo,† P. Huhtanen, ${ }^{*}$ T. Hurme, $\S$ \\ J. M. Griinari,† and K. J. Shingfield*\# ${ }^{1}$ \\ *Natural Resources Institute Finland, Nutritional Physiology, Green Technology, FI-31600 Jokioinen, Finland \\ †Department of Agricultural Sciences, University of Helsinki, PO Box 28, FI-00014 Helsinki, Finland \\ ‡Department of Agriculture for Northern Sweden, Swedish University of Agricultural Sciences, S-90183 Umeå, Sweden \\ $\S N a t u r a l$ Resources Institute Finland, Statistical Methods, Management and Production of Renewable Resources, Fl-31600 Jokioinen, Finland \\ \#Institute of Biological, Environmental and Rural Sciences, Animal and Microbial Sciences, Aberystwyth University, Aberystwyth, SY23 3EB, \\ United Kingdom
}

\section{ABSTRACT}

The potential of dietary fish oil (FO) supplements to increase milk 20:5n-3 and 22:6n-3 concentrations and the associated effects on milk fatty acid (FA) composition, intake, and milk production were examined. Four multiparous lactating cows offered a grass silage-based diet (forage:concentrate ratio $58: 42$, on a dry matter basis) supplemented with $0,75,150$, or $300 \mathrm{~g}$ of FO/d (FO0, FO75, FO150, and FO300, respectively) were used in a $4 \times 4$ Latin square with 28 -d experimental periods. Milk FA composition was analyzed by complementary silver-ion thin-layer chromatography, gas chromatography-mass spectrometry, and silver-ion HPLC. Supplements of FO decreased linearly dry matter intake, yields of energy-corrected milk, milk fat and protein, and milk fat content. Compared with FO0, milk fat content and yield were decreased by 30.1 and $40.6 \%$, respectively, on the FO300 treatment. Supplements of FO linearly increased milk 20:5n-3 and 22:6n-3 concentrations from 0.07 to 0.18 and 0.03 to $0.10 \mathrm{~g} / 100$ g of FA, respectively. Enrichment of 20:5n-3 and 22:6n3 was accompanied by decreases in 4- to 18-carbon saturated FA and increases in total conjugated linoleic acid (CLA), trans FA, and polyunsaturated FA concentrations. Fish oil elevated milk fat cis-9,trans-11 CLA content in a quadratic manner, reaching a maximum on FO150 (from 0.61 to $2.15 \mathrm{~g} / 100 \mathrm{~g}$ of FA), whereas further amounts of FO increased trans-10 18:1 with no change in trans-11 18:1 concentration. Supplements of FO also resulted in a dose-dependent appearance of 37 unique 20- and 22-carbon intermediates in milk fat. Concentrations of 16-, 18-, 20-, and 22-carbon trans FA were all increased by FO, with enrichment of trans 18:1

Received March 8, 2015.

Accepted April 27, 2015.

${ }^{1}$ Corresponding author: kes14@aber.ac.uk and trans 18:2 being quantitatively the most important. Decreases in milk fat yield to FO were not related to changes in milk trans-10,cis-12 CLA concentration or estimated milk fat melting point. Partial least square regression analysis indicated that $\mathrm{FO}$-induced milk fat depression was associated with changes in the concentrations of multiple FA in milk. Even though a direct cause and effect could not be established, a decrease in 18:0 supply in combination with increased mammary uptake of cis-11 18:1, trans-10 18:1, and trans 20- and 22-carbon FA may contribute. In conclusion, dietary FO supplements enrich 20:5n-3 and 22:6n-3 in milk, but also elevate mono- and polyenoic trans FA concentrations, and in high amounts alter the distribution of individual trans $\mathrm{FA}$ isomers.

Key words: conjugated linoleic acid, fish oil, milk fat, trans fatty acid

\section{INTRODUCTION}

Increasing evidence has shown that nutrition is an important factor involved in the onset and development of several chronic diseases in humans, including cancer, cardiovascular disease (CVD), type II diabetes, and obesity. Clinical studies implicate an excessive consumption of medium-chain SFA and trans FA as risk factors for CVD and in the etiology of insulin resistance (WHO, 2003; Shingfield et al., 2008). Observational, prospective cohort, and randomized intervention studies have contributed to a body of evidence to indicate that moderate increases in the consumption of the long-chain n-3 PUFA, 20:5n-3 and 22:6n-3, lowers CVD disease risk, decreases the incidence of sudden cardiac arrest, improves immune function, and may prevent certain cancers (Palmquist, 2009).

Milk and dairy products are a major source of 12:0, 14:0, 16:0, and total SFA in the Western diet, but also contain several other FA, including 4:0, several odd- and branched-chain FA, cis-9 18:1, and cis-9,trans-11 CLA, 
with potential to prevent the onset and development of chronic disease (Lock and Bauman, 2004; Shingfield et al., 2008). Consequently, considerable interest exists in producing milk and dairy foods containing lower amounts of medium-chain SFA and higher concentrations of cis-9 18:1, cis-9,trans-11 CLA, and long-chain n-3 PUFA for improving human health without requiring changes in consumer eating habits.

Dietary supplements of fish oil (FO) can be used to increase long-chain n-3 PUFA concentrations in ruminant milk, but enrichment varies depending on the basal diet and source of marine lipid (Chilliard et al., 2001; Shingfield et al., 2013). Supplements of FO are also effective for enriching milk fat cis-9,trans-11 CLA concentrations, increases that are also accompanied by elevated proportions of trans 18:1 and trans 18:2 isomers (Chilliard et al., 2001; Shingfield et al., 2003; Loor et al., 2005). Recent reports indicate that the FA in FO also modify ruminal biohydrogenation resulting in the formation and accumulation of 20- and 22-carbon FA containing at least a single trans double bond in sheep (Toral et al., 2010) and cattle (Kairenius et al., 2011; Shingfield et al., 2012), but the occurrence of these intermediates in bovine milk fat has not been documented.

Supplements of FO typically decrease milk fat synthesis in lactating cows (Offer et al., 1999; Donovan et al., 2000; Keady et al., 2000), a response associated with the effects of FA in FO on ruminal lipid metabolism (Loor et al., 2005). The exact cause of FO-induced milk fat depression (MFD) in lactating cows has not been established, but several hypotheses have been postulated, including increased formation of biohydrogenation intermediates that inhibit milk fat synthesis, lowered availability of 18:0 for endogenous cis-9 18:1 synthesis, and an increase in milk fat melting point (Loor et al., 2005; Shingfield and Griinari, 2007; Gama et al., 2008).

The objectives of the present investigation were (1) to evaluate the potential of dietary FO supplements to enrich milk 20:5n-3 and 22:6n-3 concentrations and the associated effects on milk FA composition and animal performance, and (2) examine the relationships between the flow of FA at the omasum, changes in milk FA composition, and milk fat synthesis to provide further insight into the possible causes of FO-induced MFD. Chemical composition of dietary ingredients and treatment effects on FA intake, ruminal microbial ecology, rumen fermentation characteristics, and flow of FA at the omasum have been reported previously (Shingfield et al., 2012).

\section{MATERIALS AND METHODS}

\section{Animals, Experimental Design, and Diets}

All experimental procedures were approved by the Animal Ethics Committee of MTT Agrifood Research Finland (Jokioinen, Finland) in accordance with the Use of Vertebrates for Scientific Purposes Act of 1985. Four multiparous (2 Finnish Ayrshire and 2 Friesian) cows fitted with a rumen cannula (i.d. $100 \mathrm{~mm}$; Bar Diamond Inc., Parma, ID), averaging $578 \pm 13.6 \mathrm{~kg}$ of BW, $159 \pm 28.5 \mathrm{DIM}$, and producing $22.3 \pm 2.42$ $\mathrm{kg}$ of milk/d were allocated at random to experimental treatments according to a $4 \times 4$ Latin square with 28-d periods. A detailed description of animal management and experimental treatments is reported elsewhere (Shingfield et al., 2006, 2012). In brief, cows were offered grass silage and a cereal-based concentrate (forage:concentrate ratio 58:42, on a DM basis) as equal meals at 0600 and $1800 \mathrm{~h}$ in an amount representing $95 \%$ of ad libitum intake measured over a period of $14 \mathrm{~d}$ immediately before the start of the experiment. Treatments comprised $0,75,150$, and $300 \mathrm{~g} / \mathrm{d}$ of ultrarefined herring and mackerel oil (EPAX 3000 TG, Pronova Biocare AS, Aalesund, Norway; designated as treatments FO0, FO75, FO150, and FO300, respectively), offered in equal amounts by mixing thoroughly with concentrate ingredients just before feeding. Cows were housed in individual tiestalls within a dedicated metabolism unit with continuous access to water and milked twice daily at 0700 and $1645 \mathrm{~h}$.

\section{Measurements, Sampling, and Chemical Analysis}

Intake and milk yield were measured daily throughout the experiment. Samples of milk were collected over 2 consecutive milkings starting at $1645 \mathrm{~h}$ on d 17, 20, 24 , and 27 of each experimental period, treated with preservative (Bronopol, Valio Ltd., Helsinki, Finland), and analyzed for milk fat, CP, and lactose by midinfrared spectroscopy (Milko-Scan 133B, Foss Electric, Hillerød, Denmark). Unpreserved milk samples were also collected at the same time, stored at $-20^{\circ} \mathrm{C}$, and composited according to milk yield until analyzed for FA composition. Ruminal administration of LiCo-ED$\mathrm{TA}$, Yb-acetate, and Cr-mordanted straw as indigestible markers to estimate flow of FA at the omasum were found to alter milk fat composition (Shingfield et al., 2006); therefore, only samples of milk collected immediately before marker administration were submitted for detailed FA analysis. 


\section{Lipid Analysis}

Following the addition of $1 \mathrm{~mL}$ of internal standard [100 mg of tritridecanoin (\#T-135, Nu-Chek Prep, Elysian, MN) dissolved in 78,600 $\mathrm{mg}$ of ethanol], lipid in a 1-mL milk sample was extracted in duplicate using ammonia, ethanol, diethyl ether, and hexane (0.2:1:2.5:2.5 $\mathrm{vol} / \mathrm{vol}$ ). Organic extracts were combined and evaporated to dryness at $40^{\circ} \mathrm{C}$ under oxygen-free nitrogen. Samples were dissolved in hexane and methyl acetate and transesterified to FAME using freshly prepared methanolic sodium methoxide (Shingfield et al., 2003).

The FAME prepared from milk fat were quantified using a GC (model 6890, Hewlett-Packard, Wilmington, DE) equipped with a flame-ionization detector (FID), automatic injector, split injection port, and a 100-m fused silica capillary column (i.d. $0.25 \mathrm{~mm}$ ) coated with a $0.2-\mu \mathrm{m}$ film of cyanopropyl polysiloxane (CP-SIL 88, Chromopack 7489, Middelburg, the Netherlands). Total FAME profile in a $2-\mu \mathrm{L}$ sample at a split ratio of 1:50 was determined using a temperature gradient program and hydrogen as a carrier gas (Shingfield et al., 2003). Injector and detector temperatures were maintained at $255^{\circ} \mathrm{C}$. Individual isomers of $18: 1$ and 18:2 were further resolved in a separate analysis under isothermal conditions at $170^{\circ} \mathrm{C}$ (Shingfield et al., 2003). Peaks were routinely identified by comparison of retention times with authentic FAME standards (GLC \#463, \#N-21/23/24M, \#U-37/39/43/54/64/85/87-M, Nu-Chek Prep; \#10-1620/-1818-4/-1840/-2001-1/-2014-5, \#11-16008, \#14-1800-5-4/-1800-6-4/-1800-7-4/-1800-8-39, \#20-1606-4/-1607-5/-1611/-1869-2/-2024-1/-2103-14/-2105-4/-2210-9/-2265-7/-2305-1-4/-2405-4/-25007/-2900-7, \#21-1211-7/-1413-7/-1615-7; \#MixtureBR2/-BR3, Larodan Fine Chemicals, Malmö, Sweden; \#L-8404/6031, \#H-6389/6639, \#O-4129, \#T-4129, Sigma-Aldrich, St. Louis, MO). Methyl esters not contained in commercially available standards were identified in milk fat based on complementary silver-ion thin-layer chromatography $\left(\mathbf{A g}^{+}-\mathbf{T L C}\right)$ and GC-MS analysis of selected samples of milk fat FAME and corresponding 4,4-dimethyloxazoline (DMOX) derivatives prepared from each fraction of FAME recovered from $\mathrm{Ag}^{+}$-TLC plates (Kairenius et al., 2011). The $\mathrm{Ag}^{+}$-TLC separation of FAME prepared from total lipid in milk fat was performed using Silica gel G plates $(200 \times$ $200 \mathrm{~mm}$ and $0.50 \mathrm{~mm}$ thickness, No. 1.13894; Merck, Darmstadt, Germany) impregnated with 5\% (wt/vol) silver nitrate in acetonitrile for $20 \mathrm{~min}$ and activated at $110^{\circ} \mathrm{C}$ for $45 \mathrm{~min}$ just before sample application. Plates were developed with a solvent comprised of hexane and diethyl ether (90:10 vol/vol) and the separated bands were visualized under UV light after spraying with a $0.2 \%$ (wt/vol) solution of $2^{\prime}, 7^{\prime}$-dichlorofluorescein in methanol (Kairenius et al., 2011). Five bands separated according to the degree of unsaturation, corresponding to methyl esters of saturated, cis- and trans-monoenoic, dienoic, and polyenoic FA containing 3 or more double bonds, were removed individually from the plate and transferred to clean test tubes. Fractionated FAME were recovered from the silica after the addition of 1 $\mathrm{mL}$ of methanol, $2 \mathrm{~mL}$ of hexane, and $1 \mathrm{~mL}$ of $6 \%$ (wt/ vol) aqueous sodium chloride and the hexane-soluble phase was dried over anhydrous sodium sulfate. Each FAME fraction was analyzed by GC-FID and GC-MS and used to prepare DMOX derivatives.

Electron ionization spectra of FAME and DMOX derivatives were recorded using an identical GC equipped with a quadrupole mass spectrometer (Model 5973N, Agilent Technologies Inc., Wilmington, DE), operated at $230^{\circ} \mathrm{C}$ in the positive electron ionization mode under an ionization voltage of $70 \mathrm{eV}$. Total ion chromatograms in $4-\mu \mathrm{L}$ samples of FAME or DMOX at a split ratio of 1:50 were obtained with the same temperature gradient applied for the GC analysis of FAME using helium as a carrier gas (Kairenius et al., 2011). The injector and interface temperatures were maintained at 255 and $240^{\circ} \mathrm{C}$, respectively. Preparation of DMOX derivatives and interpretation mass spectra were in accordance with earlier reports (Halmemies-BeauchetFilleau et al., 2011; Kairenius et al., 2011).

When available, the deduced FA structure was verified by comparison with the mass spectrum of DMOX derivatives prepared from authentic FAME standards and cross-referencing with an online reference spectra library (http://lipidlibrary.aocs.org/ms/masspec. html). Given that GC-MS analysis of DMOX derivatives does not discriminate between geometric isomers, a cis or trans double bond configuration for monoenoic FA was established based on $\mathrm{Ag}^{+}-\mathrm{TLC}$. Fractionation of FAME by $\mathrm{Ag}^{+}$-TLC did not resolve methyl esters of dienoic, trienoic, tetraenoic, pentaenoic, and hexaenoic FA. Therefore, double-bond geometry of FA containing 2 or more double bonds was deduced based on comparisons of retention times of corresponding FAME determined by GC-FID and the known elution order of authentic geometric isomers of $\Delta 9,1218: 2$ and $\Delta 9,12,15$ 18:3 methyl esters (\#L-8404 and \#L-6031, respectively, Sigma-Aldrich).

The distribution of CLA isomers in milk was determined using a $\mathrm{Ag}^{+}$-HPLC system (Model 1090; Hewlett-Packard) equipped with 2 silver-impregnated silica columns (Chrom-Spher 5 Lipids, $250 \times 4.6 \mathrm{~mm}, 5$ $\mu \mathrm{m}$ particle size; Varian Ltd., Walton-on-Thames, UK) coupled in series. Methyl esters of CLA were separated under isocratic conditions at $22^{\circ} \mathrm{C}$ using $0.1 \%$ ( $\mathrm{vol} / \mathrm{vol}$ ) acetonitrile in heptane as the mobile phase at a flow rate of $1 \mathrm{~mL} / \mathrm{min}$ and monitoring column effluent at 
233 and $210 \mathrm{~nm}$ (Shingfield et al., 2003). Isomers of CLA were identified using a standard containing a mixture of CLA methyl esters (\#O-5632, Sigma-Aldrich). Trans isomers of CLA were well resolved, whereas baseline separation of cis, trans and trans, cis isomers was achieved using a manually operated switching valve (model 7000, Rheodyne, L.P., Cotati, CA) that allowed this fraction to be recycled between columns.

Milk FA composition was expressed as a weight percentage of total FA using theoretical relative response factors (Halmemies-Beauchet-Filleau et al., 2011) to account for the carbonyl carbon deficiency in the FID response for FAME containing 4- to 10-carbon atoms. Tritridecanoin was used as an internal standard to determine the FA content of milk fat (Shingfield et al., 2003). Concentrations of CLA isomers were calculated based on proportionate peak area responses determined by HPLC and the sum of trans-7,cis-9 CLA, trans8,cis-10 CLA, and cis-9,trans-11 CLA weight percentage determined by GC-FID analysis.

Mean milk fat melting point was calculated as the sum of the product of molar proportions and melting point for all FA identified in milk fat, assuming that the contribution of individual FA to the overall melting point of milk fat is additive and minimal variation in the nonrandom positional distribution of FA in milk triacylglycerols (Toral et al., 2013). Melting points of the major FA were obtained from reports in the literature (Small, 1986; Gunstone et al., 1994; Jensen and Patton, 2000) and an online LipidBank database (http://www. lipidbank.jp). For 20- and 22-carbon PUFA, melting points not reported elsewhere were estimated based on comparisons of melting points for neighboring methyl esters in the GC-FID chromatogram and known differences in the melting point due to differences in double bond number, position, and geometry reported for 18-carbon unsaturated FA.

\section{Statistical Analysis}

Measurements of DMI, milk yield, and milk composition made from d 17 to 27 for each experimental period were averaged before statistical analysis. Experimental data were analyzed by ANOVA for a $4 \times 4$ Latin square design with a statistical model that included the fixed effects of period and treatment and the random effect of cow using the MIXED procedure of SAS (SAS Institute Inc., Cary, NC). Sum of squares were further separated into polynomial contrasts to test for the significance of linear and quadratic components of the response to dietary FO supplementation. Least squares means \pm standard error of the mean are reported and treatment effects were considered significant at $P<0.05$. Differ- ences at $P>0.05$ to $P=0.10$ were considered as a trend toward significance.

Associations between FA flow at the omasum (Shingfield et al., 2012), with milk fat yield and the output of FA in milk for individual cows, were evaluated by linear regression analysis using the REG procedure of SAS. Relationships between a dependent and independent variable were classified as either nonexistent $(0-0.1)$, weak (0.1-0.3), moderate $(0.3-0.5)$, or strong (0.5-1) according to the adjusted correlation coefficient of the linear regression between individual variables.

Relationships between milk fat content and milk fat yield with changes in the concentration of all identified FA in milk were further analyzed by partial least squares regression (PLS) using the PLS procedure of SAS, with milk fat yield and milk fat content as response variables and the proportion of individual FA in milk as an explanatory variable to produce correlation loading plots.

Such an analysis provides a descriptive overview of experimental data and compliments the analysis by linear regression, even though the assumptions of the PLS model are not met in full (i.e., observations are not truly independent). The concept underpinning the PLS analysis is that when multiple explanatory variables exist, relatively few factors account for most of the variation in an observed response. Analysis by PLS attempts to extract latent factors to account for as much of the manifest factor variation as possible, while also modeling observed responses (Tobias, 1995). In the present analysis, the number of factors was set to 2 (sum of FA in milk based on carbon chain length and degree of unsaturation, 18-carbon FA, and isomers of 20 - to $22 \mathrm{FA}$ ) or all 3 factors (for all identified FA) using the leave-one-out cross validation procedure, based on minimizing the predicted residual sum of squares. Variables in the PLS analysis were centered and scaled (standardized) to a mean of 0 and standard deviation of 1 .

\section{RESULTS}

\section{Intake and Milk Production}

Effects of FO treatments on FA intake have been reported previously (Shingfield et al., 2012). In brief, FO supplements increased linearly $(P<0.001)$ the intakes of 20:5n-3, 22:6n-3, and total FA from 0,0 , and 587 to $44.7,28.3$, and $778 \mathrm{~g} / \mathrm{d}$, respectively. Dietary FO supplements decreased linearly $(P<0.001)$ the intakes of silage DM and total DM (Table 1). Fish oil tended $(P=0.09)$ to lower milk yield in a quadratic manner, with the greatest response to FO300, and decreased linearly $(P<0.05)$ the yields of ECM, fat, protein, and 
Table 1. Effect of dietary fish oil supplements on DMI, milk production, and milk fat melting point in lactating cows fed grass silage-based diets

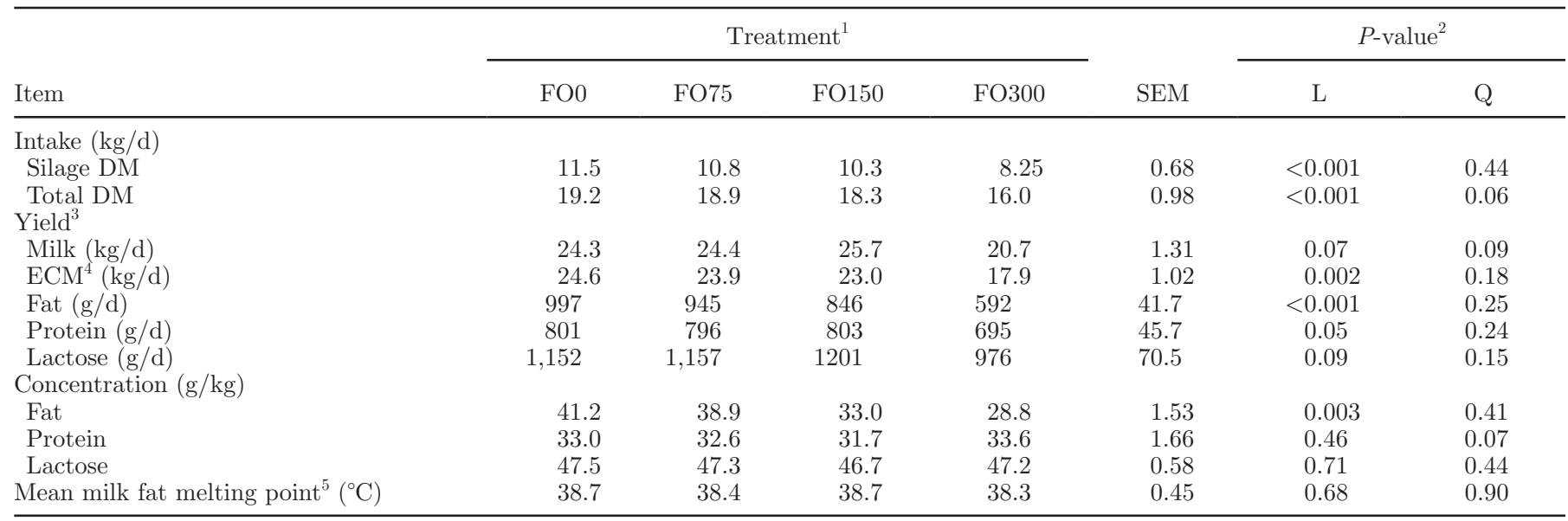

${ }^{1}$ Refers to grass silage-based diet (forage:concentrate ratio 58:42, on a DM basis) supplemented with 0, 75, 150 or 300 g/d of fish oil (FO0, FO75, FO150, and FO300, respectively).

${ }^{2}$ Significance of linear (L) and quadratic (Q) components of the response to dietary fish oil supplements.

${ }^{3}$ Average of measurements made from d 17-27 of each experimental period.

${ }^{4}$ Energy-corrected milk yield calculated as milk yield, $\mathrm{kg} / \mathrm{d} \times[(38.3 \times$ fat, $\mathrm{g} / \mathrm{kg})+(24.2 \times$ protein, $\mathrm{g} / \mathrm{kg})+(16.54 \times \mathrm{lactose}, \mathrm{g} / \mathrm{kg})+20.7] / 3140$ (Sjauna et al., 1990).

${ }^{5}$ Calculated as the sum of the product of molar proportions and melting point for all FA identified in milk fat, assuming that the contribution of individual FA to the overall melting point of milk fat is additive.

milk fat content (Table 1). Decreases in milk fat concentration and milk constituent yields to FO reached a plateau by d 17, with no further changes with time on diet (sampling time by treatment interactions, $P>$ 0.10 ; data not presented). Supplements of FO had no effect $(P>0.05)$ on calculated mean milk fat melting point (Table 1).

\section{Milk FA Composition}

Analysis of fractionated FAME and corresponding DMOX derivatives by GC-FID and GC-MS allowed 196 baseline separated or coeluting FA to be detected in the milk fat GC-FID chromatogram. Of these, 174 were able to be identified, including 37 unique FA not previously reported in milk from cows fed FO.

Supplements of FO altered milk fat composition, changes characterized by linear decreases $(P<0.05)$ in 4- to 14-carbon SFA, 16:0, 18:0, total SFA, and cis 18:1, and linear or quadratic increases $(P \leq 0.05)$ in total 16:1, 16:2, 10-O-18:0, 13-O-18:0, trans 18:1, total 18:2, total CLA, 20:5n-3, 22:5n-3, 22:6n-3, and total trans FA (Table 2). However, FO had no effect $(P$ $>0.05$ ) on milk $18: 2 \mathrm{n}-6$ and $18: 3 \mathrm{n}-3$ concentrations (Table 2$)$. Fish oil linearly decreased $(P<0.05)$ milk fat cis-9 10:1/10:0, cis-9 12:1/12:0, and cis-9,trans-11 18:1/trans-11 18:1 concentration ratios, and increased linearly $(P<0.05)$ cis-9 16:1/16:0 and cis-9 18:1/18:0, but had no effect $(P>0.05)$ on the cis-9 14:1/14:0 ratio (Table 2).
Fish oil increased linearly $(P<0.05)$ milk fat cis $16: 1$ and trans 16:1 concentrations, with the majority of the increase due to enrichment of cis-9 16:1 and trans-9, -10, and -11 16:1 (Table 3). Supplements of FO also increased in a linear or quadratic manner $(P<0.05)$ the abundance of all identified 16:2 isomers in milk (Table 3).

Supplements of FO had no effect $(P>0.05)$ on milk 18:1 concentration, but resulted in trans 18:1 replacing cis 18:1 (Table 2). Decreases in the proportion of total cis 18:1 in response to FO were, for the most part, due to linear decreases $(P<0.01)$ in cis-9 18:1 that were only partially compensated for by linear or quadratic increases $(P \leq 0.01)$ in cis-11, -13 , and $-1518: 1$ concentrations (Table 4 ). With the exception of trans-4 and $-518: 1$, FO resulted in linear or quadratic increases $(P<0.05)$ in the abundance of all analyzed trans 18:1 isomers (Table 4). For all treatments, trans-11 was quantitatively the most important isomer, accounting for proportionately $0.350,0.396,0.478$, and 0.404 of total trans 18:1, for FO0, FO75, FO150, and FO300, respectively. However, increases in the amount of $\mathrm{FO}$ elevated $(P \leq 0.01)$ milk trans-10 18:1 concentration in a quadratic manner, with the greatest increase from FO150 to FO300 (Table 4).

Supplements of FO increased total milk fat CLA content in a quadratic manner $(P<0.05)$, with the highest enrichment on the FO150 treatment. Most of the increase in CLA content was attributable to higher cis-9,trans-11 CLA concentrations, and to a lesser ex- 
Table 2. Effect of dietary fish oil supplements on milk FA composition in lactating cows fed grass silage-based diets

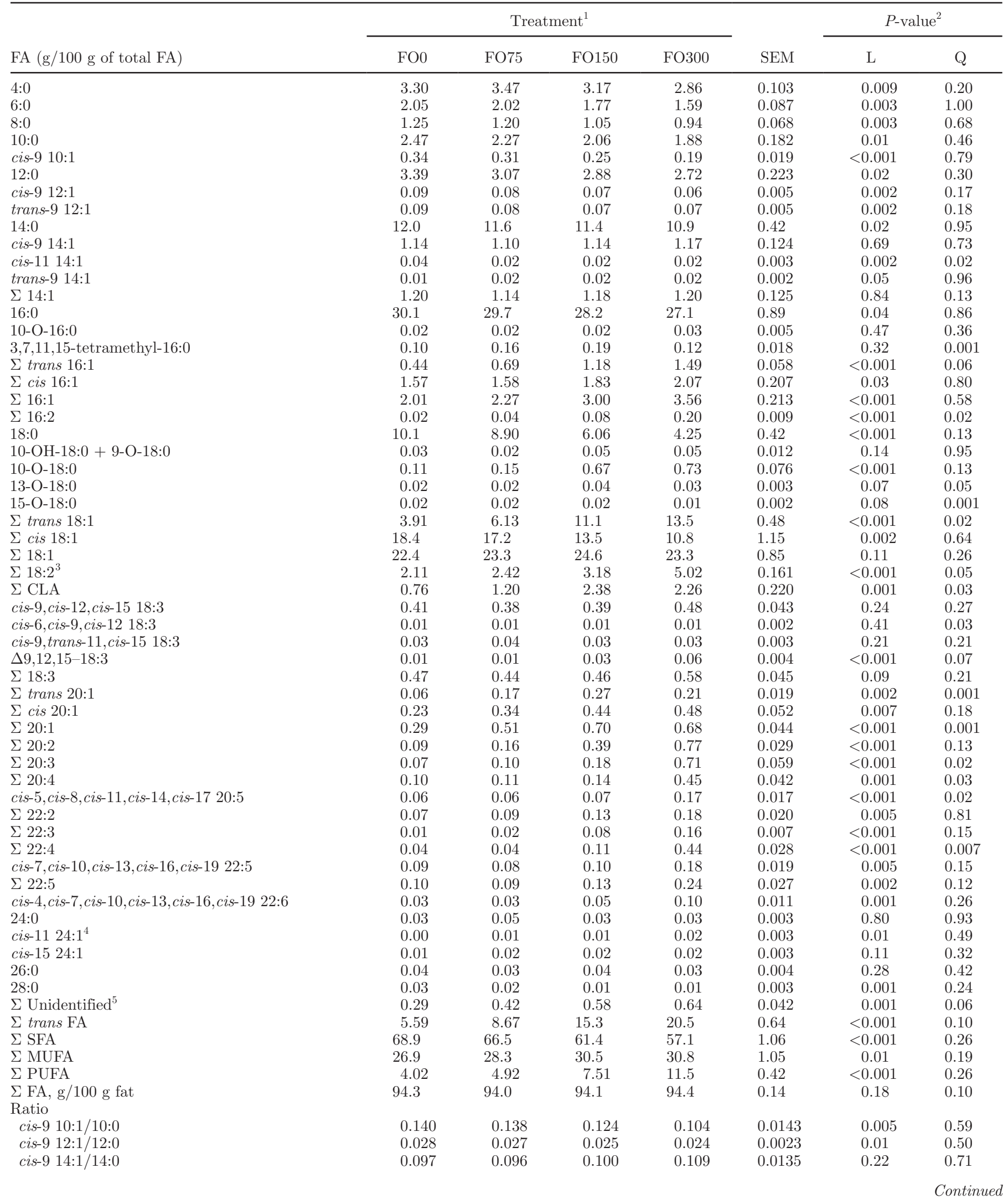


Table 2 (Continued). Effect of dietary fish oil supplements on milk FA composition in lactating cows fed grass silage-based diets

\begin{tabular}{|c|c|c|c|c|c|c|c|}
\hline \multirow[b]{2}{*}{$\mathrm{FA}(\mathrm{g} / 100 \mathrm{~g}$ of total FA) } & \multicolumn{4}{|c|}{ Treatment $^{1}$} & \multirow[b]{2}{*}{ SEM } & \multicolumn{2}{|c|}{$P$-value ${ }^{2}$} \\
\hline & FO0 & FO75 & FO150 & FO300 & & $\mathrm{L}$ & $\mathrm{Q}$ \\
\hline cis-9 18:1/18:0 & 1.743 & 1.825 & 2.031 & 2.165 & 0.1728 & 0.03 & 0.73 \\
\hline cis-9,trans-11 CLA/trans-11 18:1 & 0.450 & 0.442 & 0.412 & 0.391 & 0.0395 & 0.05 & 0.88 \\
\hline
\end{tabular}

${ }^{1}$ Refers to grass silage-based diet (forage:concentrate ratio 58:42, on a DM basis) supplemented with 0, 75, 150 or 300 g/d of fish oil (FO0, FO75, FO150, and FO300, respectively).

${ }^{2}$ Significance of linear (L) and quadratic (Q) components of the response to dietary fish oil supplements.

${ }^{3}$ Total 18:2 excluding isomers of CLA.

${ }^{4}$ Coelutes with cis-9, ,is- 12 , cis-15, cis-18 21:4.

${ }^{5}$ Sum of 22 unidentified FA.

tent, trans-7,cis-9 CLA (Table 4). Increasing amounts of FO also altered the relative abundance $(P<0.05)$ of numerous minor CLA isomers in milk, but had no effect $(P>0.05)$ on milk fat trans-10, cis-12 CLA and trans-9,trans-11 CLA concentrations (Table 4). Fish oil also altered the distribution of nonconjugated 18:2 FA in milk fat, changes characterized by linear or quadratic increases $(P<0.05)$ in the concentrations of most isomers containing one or more trans double bonds (Table 4).

Dietary FO supplements resulted in the appearance of multiple 20- to 22-carbon FA in milk (Table 5).
Partial gas chromatograms indicating the separation of methyl esters of long-chain FA prepared from milk of a cow fed the FO300 treatment eluting between 40.4 to 47.1 and 47.2 to 54.2 min are shown in Figures 1 and 2 , respectively.

Milk from cows fed FO contained cis-14 20:1, trans-9 to $-1520: 1$, positional and geometric isomers of $20: 2$ (n $=9)$ and 20:3 $(\mathrm{n}=7)$, and an unusual 20:4 intermediate not contained in FO (Table 5). Fish oil also resulted in linear or quadratic increases $(P \leq 0.05)$ in milk 20:2n-6, 20:3n-3, 20:4n-6, and 20:4n-3 concentrations (Table 5). Enrichment of all cis 20-carbon PUFA in milk were

Table 3. Effect of dietary fish oil supplements on milk 16:1 and 16:2 FA composition in lactating cows fed grass silage-based diets

\begin{tabular}{|c|c|c|c|c|c|c|c|}
\hline \multirow[b]{2}{*}{ FA $(\mathrm{mg} / 100 \mathrm{~g}$ of total FA) } & \multicolumn{4}{|c|}{ Treatment $^{1}$} & \multirow[b]{2}{*}{ SEM } & \multicolumn{2}{|c|}{$P$-value ${ }^{2}$} \\
\hline & FO0 & FO75 & FO150 & FO300 & & $\mathrm{L}$ & Q \\
\hline cis-9 16:1 & 1344 & 1372 & 1577 & 1858 & 202.4 & 0.03 & 0.74 \\
\hline cis-10 16:1 & 13.8 & 6.50 & 12.8 & 19.7 & 3.17 & 0.06 & 0.09 \\
\hline cis-1116:1 & 30.1 & 26.4 & 53.0 & 43.6 & 5.88 & 0.04 & 0.16 \\
\hline cis-12 16:1 & 25.3 & 51.0 & 82.8 & 60.9 & 7.28 & 0.01 & 0.005 \\
\hline trans-5 16:1 & 8.85 & 11.9 & 19.6 & 17.9 & 1.29 & 0.004 & 0.02 \\
\hline trans $-6+7 \quad 16: 1$ & 34.6 & 49.7 & 74.2 & 89.0 & 6.51 & 0.001 & 0.24 \\
\hline trans-8 16:1 & 12.5 & 23.6 & 61.3 & 143 & 8.8 & $<0.001$ & 0.06 \\
\hline trans-9 16:1 & 184 & 298 & 512 & 564 & 48.4 & 0.001 & 0.09 \\
\hline trans-10 16:1 & 8.45 & 37.4 & 86.8 & 167 & 9.56 & $<0.001$ & 0.70 \\
\hline trans-11 16:1 & 23.2 & 55.8 & 166 & 248 & 14.1 & $<0.001$ & 0.36 \\
\hline trans-12 16:1 & 138 & 159 & 170 & 185 & 16.8 & 0.13 & 0.64 \\
\hline cis-10,cis-14 16:2 & 0.00 & 0.75 & 0.45 & 8.78 & 0.761 & $<0.001$ & 0.006 \\
\hline
\end{tabular}

${ }^{1}$ Refers to grass silage-based diet (forage:concentrate ratio 58:42, on a DM basis) supplemented with 0, 75, 150 or 300 g/d of fish oil (FO0, FO75, FO150, and FO300, respectively).

${ }^{2}$ Significance of linear (L) and quadratic (Q) components of the response to dietary fish oil supplements.

${ }^{3}$ Coelutes with trans-14 16:1.

${ }^{4}$ Double bond position and geometry indeterminant. 
Table 4. Effect of dietary fish oil supplements on milk 18:1 and 18:2 FA composition in lactating cows fed grass silage-based diets

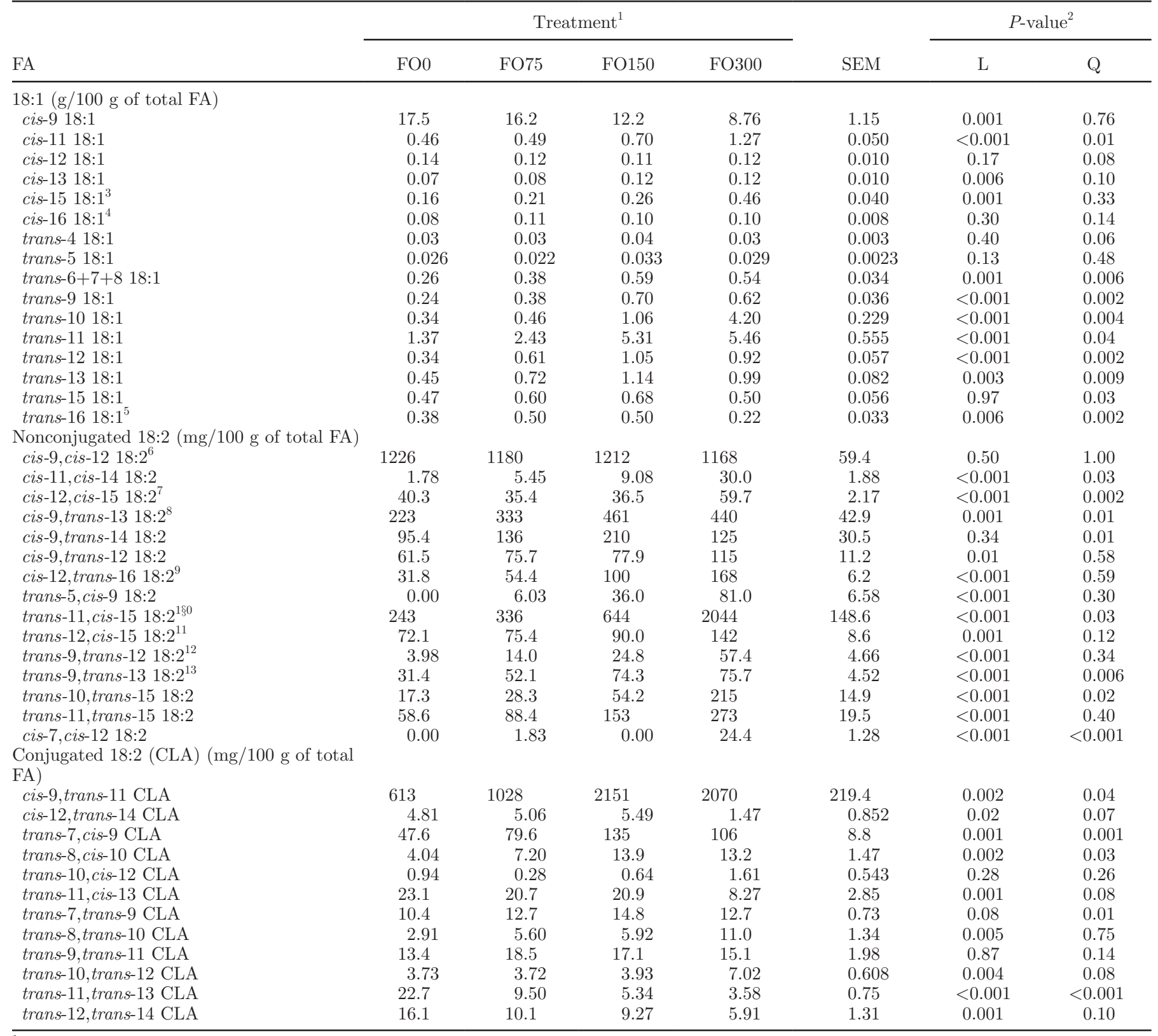

${ }^{1}$ Refers to grass silage-based diet (forage:concentrate ratio 58:42, on a DM basis) supplemented with 0, 75, 150 or $300 \mathrm{~g} / \mathrm{d}$ of fish oil (FO0, FO75, FO150, and FO300, respectively).

${ }^{2}$ Significance of linear (L) and quadratic (Q) components of the response to dietary fish oil supplements.

${ }^{3}$ Coelutes with trans-10,trans-14 18:2.

${ }^{4}$ Coelutes with trans-10,cis-14 18:2, cis-9,trans-15 18:2, cis-8,cis-12 18:2, and trans-8,cis-15 18:2.

${ }^{5}$ Coelutes with trans-5,trans-10 18:2 and trans-5,trans-11 18:2.

${ }^{6}$ Coelutes with cis-9, cis-15 18:2 and cis-9,cis-14 18:2.

${ }^{7}$ Coelutes with cis-12,cis-16 18:2 and cis-13,cis-16 18:2.

${ }^{8}$ Coelutes with cis-10,trans-14 18:2, trans-10,trans-13 18:2, and trans-11,trans-14 18:2.

${ }^{9}$ Coelutes with trans-9,cis-12 18:2 and trans-11,cis-16 18:2.

${ }^{10}$ Coelutes with trans-10, cis-15 18:2.

${ }^{11}$ Coelutes with cis-11 19:1, cis-11,cis-16 18:2, cis-11,cis-15 18:2, and cis-10,cis-15 18:2.

${ }^{12}$ Coelutes with trans-9,trans-14 18:2.

${ }^{13}$ Coelutes with cis-5,trans-9 $18: 2$. 
Table 5. Effect of dietary fish oil supplements on milk 20-, 21-, and 22-carbon FA composition in lactating cows fed grass silage-based diets

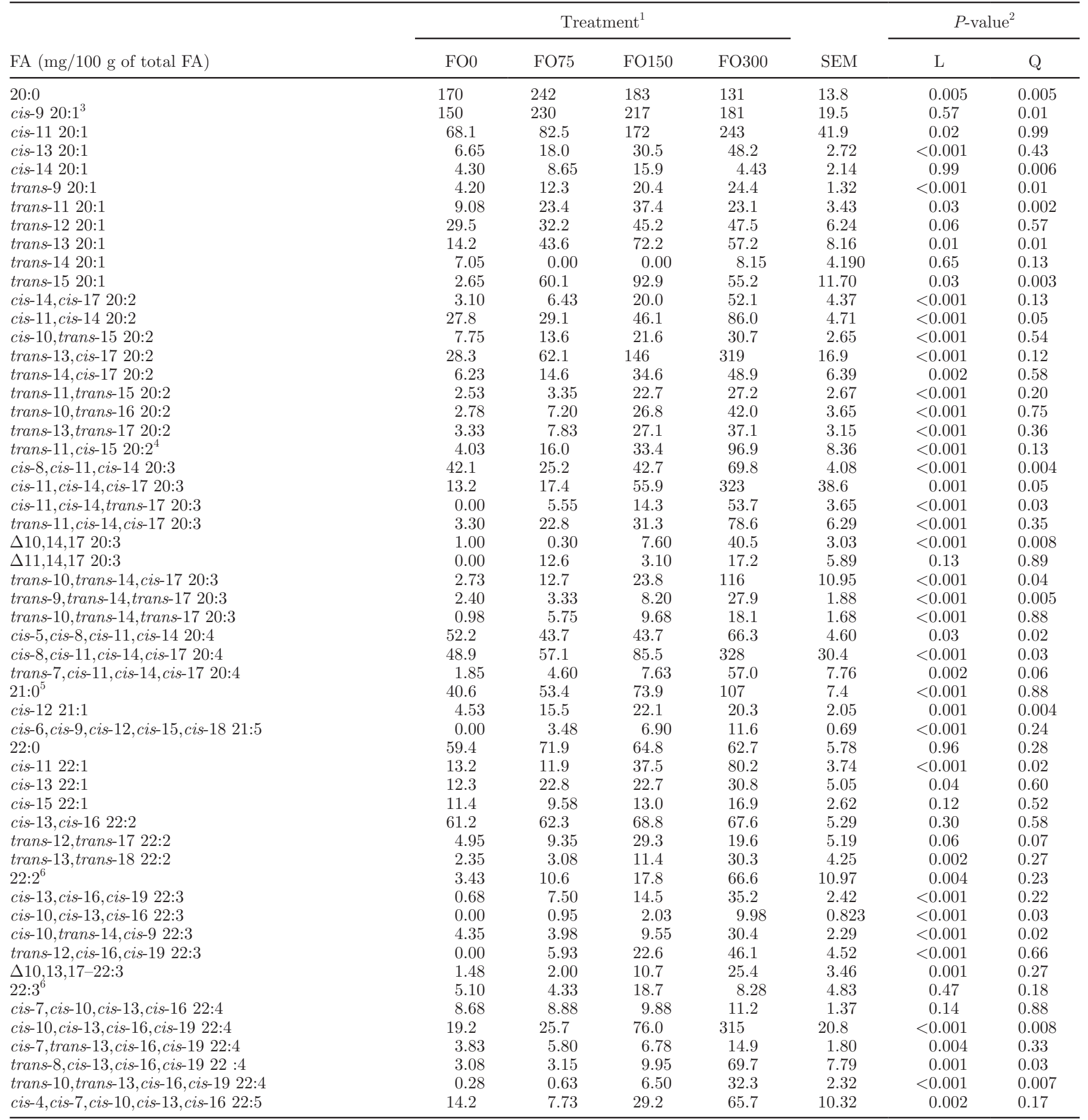

${ }^{1}$ Refers to grass silage-based diet (forage:concentrate ratio 58:42, on a DM basis) supplemented with 0, 75, 150 or 300 g/d of fish oil (FO0, FO75, FO150, and FO300, respectively).

${ }^{2}$ Significance of linear (L) and quadratic (Q) components of the response to dietary fish oil supplements.

${ }^{3}$ Coelutes with trans-14 20:1.

${ }^{4}$ Contains trans-10,cis-16 20:2 as a minor component.

${ }^{5}$ Contains trans-9,trans-15 20:2 as a minor component.

${ }^{6}$ Double bond position and geometry indeterminant. 


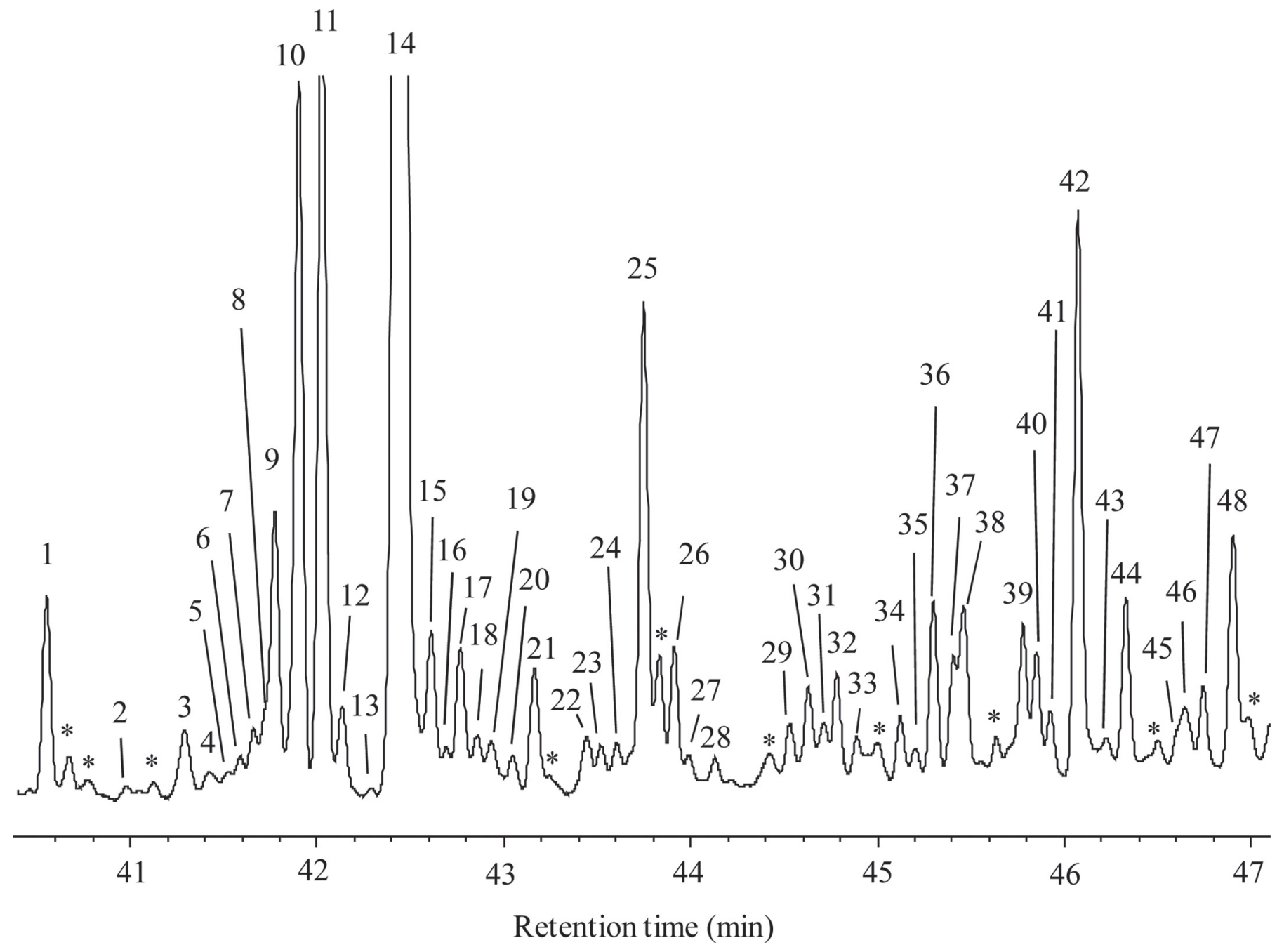

Figure 1. Partial gas chromatogram indicating the separation of FAME prepared from milk fat of cows fed a grass silage-based diet supplemented with $300 \mathrm{~g} / \mathrm{d}$ of fish oil. Peaks were identified based GC-MS analysis of FAME and corresponding 4,4-dimethyloxaline derivatives after prior fractionation of FAME by silver-ion thin-layer chromatography. Parenthesis indicate tentative geometry of double bonds as inferred based on retention times and elution order of FAME during GC analysis relative to authentic standards. Peak identification: $1=20: 0 ; 2=$ cis-6,cis-9,cis-12 18:3; 3 = unresolved trans-9,trans-12,cis-15 18:3 and cis-9,cis-12,trans-15 18:3; 4 = unresolved trans-9 20:1 and trans-10 20:1; $5=$ trans-11 20:1; $6=$ trans-12 20:1; $7=$ trans-13 20:1; $8=$ trans-14 20:1; $9=$ cis-9 20:1; $10=$ unresolved cis-11 20:1 and trans-15 20:1; $11=$ cis-9,cis-12,cis-15 18:3; $12=$ cis-13 20:1; $13=$ cis-14 20:1; $14=$ cis-9,trans-11 18:2; $15=$ trans-9,cis-11 18:2; $16=$ trans-11,trans-15 20:2; $17=$ unresolved 21:0 and trans-9,trans-15 20:2; $18=$ trans-10,trans-16 20:2; $19=$ trans -11, cis- 13 18:2; $20=$ trans- 13, trans $-1720: 2 ; 21=$ trans -11 , cis- 15 20:2; $22=$ trans-11,trans-13 18:2; $23=$ unresolved trans-9,trans-11 18:2, trans-8,trans-10 18:2, and trans-7,trans-9 18:2; 24=cis-10,trans-15 20:2; $25=$ trans-13,cis-17 20:2; $26=$ cis-11,cis-14 20:2; $27=$ cis-12 21:1; $28=$ trans-14,cis-17 20:2; $29=$ cis-9,trans-11,cis-15 18:3; 30 = cis-14,cis-17 $20: 2 ; 31=($ trans $)-9,($ trans $)-14,($ trans $)-1720: 3 ; 32=22: 0 ; 33=($ trans $)-10,($ trans $)-14,($ trans $)-1720: 3 ; 34=($ cis $)-10,($ trans $)-14,($ trans $)-17$ 20:3 or (trans)-10,(cis)-14,(trans)-17 20:3; $35=($ cis $)-11,($ trans $)-14,($ trans $)-1720: 3$ or (trans)-11,(cis)-14,(trans)-17 20:3; 36 = cis-8, cis-11,cis-14 20:3; 37 $=($ cis $)-11,($ cis $)-14,($ trans $)-17$ 20:3; $38=($ trans $)-10,($ trans $)-14,($ cis $)-1720: 3 ; 39=$ cis-11 22:1; $40=($ trans $)-11,($ cis $)-14,($ cis $)-17$ 20:3; $41=$ cis-13 $22: 1 ; 42=$ cis-11,cis-14,cis-17 20:3; $43=$ cis-15 22:1; $44=$ cis-5,cis-8,cis-11,cis-14 20:4; $45=23: 0 ; 46=$ trans-12,trans-17 22:2; $47=$ trans13,trans-18 22:2; $48=22: 2$ double-bond position and geometry indeterminant; asterisks $(*)=$ unidentified peaks.

also accompanied by linear or quadratic increases $(P<$ $0.05)$ in the concentration of 20-carbon FA containing one or more trans double bonds (Table 5).

Supplements of FO increased $(P<0.05)$ in a linear or quadratic manner milk cis-11 $22: 1$ and cis-13 22:1 concentrations and the abundance of $22: 2(\mathrm{n}=2), 22: 3$ $(\mathrm{n}=2)$, and 22:4 $(\mathrm{n}=3)$ isomers containing at least a single trans double bond (Table 5). Furthermore, FO enriched in a linear or a quadratic manner $(P<0.05)$ concentrations of all cis 22-carbon PUFA and numerous trans-containing 22-carbon intermediates (Table 5). No 20-, 21-, and 22-carbon conjugated FA were detected in milk fat. Dietary FO supplements had rather small $(P$ $\leq 0.05)$ or no effect $(P>0.05)$ on the concentrations of odd- and branched-chain FA (Supplemental Table S1, http://dx.doi.org/10.3168/jds.2015-9548). 

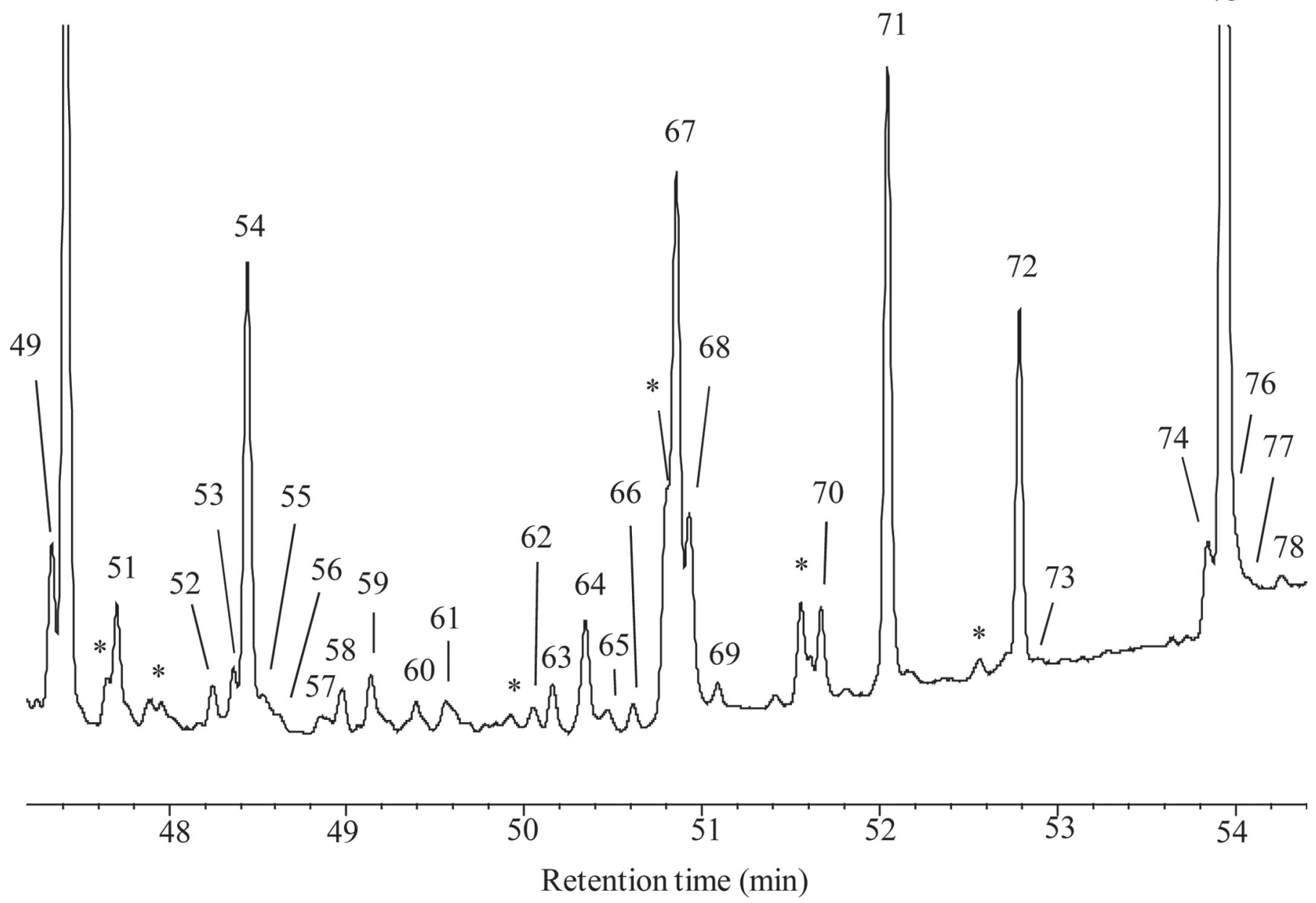

Figure 2. Partial gas chromatogram indicating the separation of FAME prepared from milk fat of cows fed a grass silage-based diet supplemented with $300 \mathrm{~g} / \mathrm{d}$ of fish oil. Peaks were identified based GC-MS analysis of FAME and corresponding 4,4-dimethyloxaline derivatives after prior fractionation of FAME by silver-ion thin-layer chromatography. Parenthesis indicate tentative geometry of double bonds as inferred based on retention times and elution order of FAME during GC analysis relative to authentic standards. Peak identification: $49=($ trans $)$-7,(cis)11,(cis)-14,(cis)-17 20:4; $50=$ cis-8,cis-11,cis-14,cis-17 20:4; $51=$ cis-13,cis-16 22:2; $52=\Delta 10,13,17-22: 3 ; 53=24: 0 ; 54=$ cis-5,cis-8, cis-11,cis14,cis-17 20:5; $55=($ cis $)-10,($ trans $)-14,($ cis $)-1922: 3 ; 56=22: 3$ double-bond position and geometry indeterminant; $57=$ cis- 10, cis- 13, cis-16 $22: 3$; $58=($ trans $)-12,($ cis $)-16,($ cis $)-1922: 3 ; 59=$ unresolved cis-11 24:1 and cis-9,cis-12,cis-15,cis-18 21:4; $60=$ cis-15 24:1; $61=$ cis-13,cis-16,cis-19 $22: 3 ; 62=$ cis-7,cis-10,cis-13,cis-16 22:4; $63=$ (trans)-10,(trans)-13,(cis)-16,(cis)-19 22:4; $64=($ trans $)-8,($ cis $)-13,($ cis $)-16,($ cis $)-19$ 22:4; 65 = cis-6,cis-9,cis-12,cis-15,cis-18 21:5; $66=$ (cis)-7,(trans)-13,(cis)-16,(cis)-19 22:4; $67=$ cis-10,cis-13,cis-16,cis-19 22:4; $68=$ cis-4,cis-7,cis-10,cis13, cis-16 22:5; $69=10-\mathrm{O}-16: 0 ; 70=26: 0 ; 71=$ cis-7, cis-10,cis-13,cis-16,cis-19 22:5; $72=$ cis-4, cis-7, cis-10,cis-13,cis-16,cis-19 22:6; $73=27: 0 ; 74$ $=$ unresolved 10-OH-18:0 and 9-O-18:0; $75=10-\mathrm{O}-18: 0 ; 76=13-\mathrm{O}-18: 0 ; 77=15-\mathrm{O}-18: 0 ; 78=28: 0 ;$ asterisks $(*)=$ unidentified peaks.

\section{Milk FA Output}

Supplements of FO progressively lowered $(P<0.01)$ the secretion of total FA in milk (Supplemental Table S2; http://dx.doi.org/10.3168/jds.2015-9548), and resulted in linear decreases $(P<0.01)$ in the output of 4- to 14-carbon, 16- and 18- carbon FA, and total 18:1 (Figure 3), as well as linear or quadratic $(P<0.05)$ increases in the secretion of trans-10 18:1, trans-11 18:1, total trans FA (Figure 3), total PUFA, total 20-carbon FA, 20:5n-3, 22:5n-3, and 22:6n-3 (Figure 4).

\section{Relationship Between FA Flow at the Omasum and Milk FA Output}

Associations between the flow of selected 16- to 22-carbon FA at the omasum to FO treatments (Shingfield et al., 2012) and milk fat yield are shown in Supplemental Table S3 (http://dx.doi.org/10.3168/ jds.2015-9548). Across all treatments a close $(P<$ 0.01) positive relationship existed between milk fat yield and the flow of 18:0 (adjusted $\mathrm{R}^{2}=0.52$ ), and a negative relationship $(P<0.01)$ between milk fat 


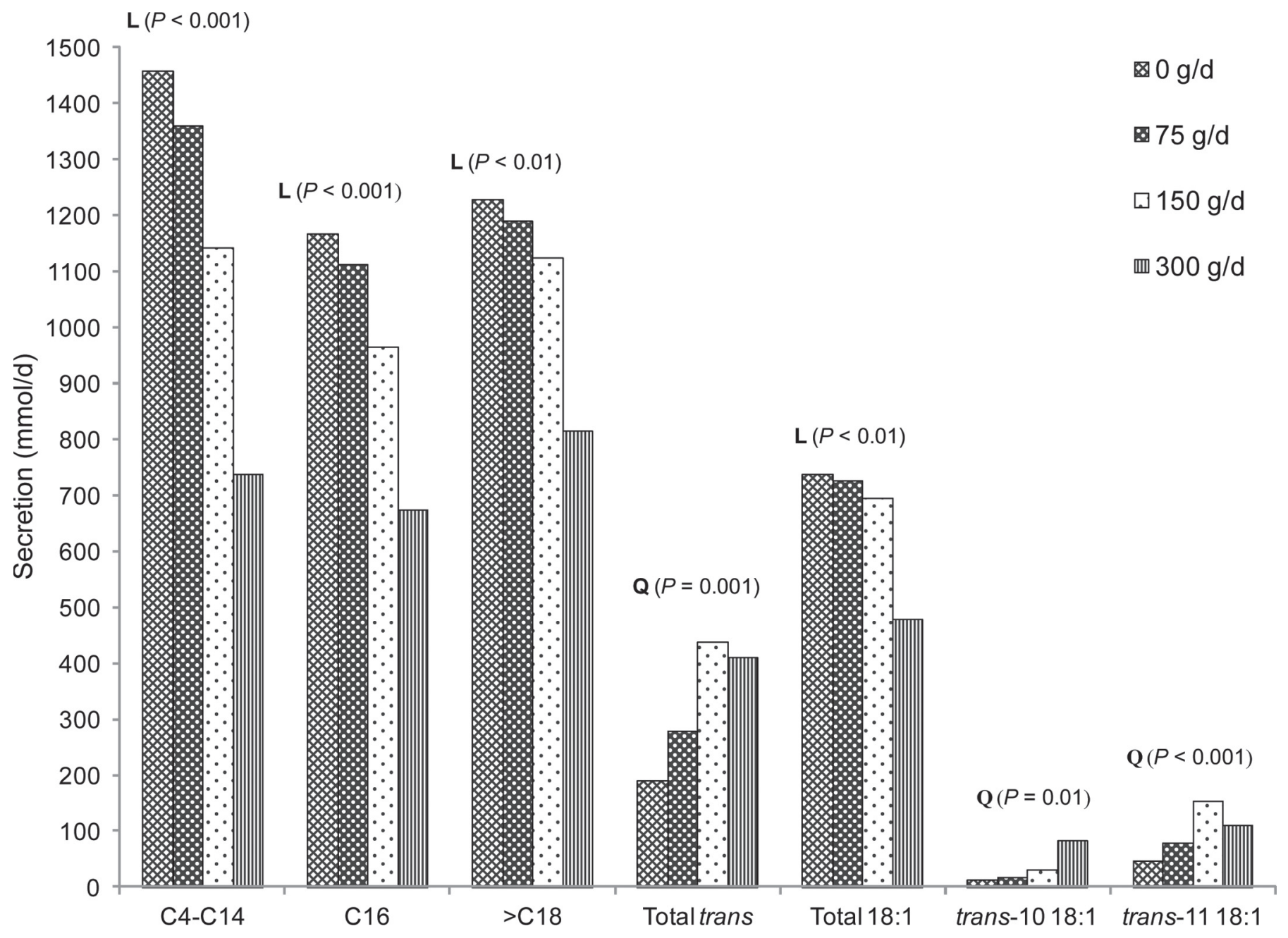

Figure 3. Effect of dietary fish oil supplements on the secretion of 4- to 14-carbon (C4-C14), total 16-carbon (C16), total $\geq 18$-carbon (>C18), total trans, total 18:1 fatty acids, trans-10 18:1, and trans-11 18:1 in milk of lactating cows fed grass silage-based diets. L and Q indicate linear and quadratic components of the response to treatments, respectively.

yield and the flow of total 18:2, 20:3, 20:4, 22:4, and $22: 5 \mathrm{FA}$ at the omasum (adjusted $\mathrm{R}^{2}=0.61,0.52$, $0.56,0.54$, and 0.52 , respectively). Further exploration of the data revealed that decreases in milk fat output were associated $(P<0.01)$ with an increase in the flow of cis-11 18:1, trans-10 18:1, trans-10, cis- 15 18:2 + trans-11,cis-15 18:2, cis-9,trans-12 18:2, trans12,cis-15 18:2, trans-11,trans-15 18:2, trans-9,trans-12 18:2, trans-10,trans-15 18:2, trans-11,trans-14 18:2, and trans-9,cis-12 18:2 (adjusted $\mathrm{R}^{2}=0.59,0.50,0.57$, $0.59,0.50,0.57,0.64,0.51,0.53$, and 0.63 , respectively), but not $(P>0.05)$ with trans-11 18:1 or cis-9,trans-11 CLA at the omasum (adjusted $\mathrm{R}^{2} \leq 0.12$ ). In contrast, the association of milk fat yield with the flow of total CLA or the flow of specific CLA isomers was relatively weak (adjusted $\mathrm{R}^{2} \leq 0.22 ; P>0.05$ ), with exception of a close positive relationship $(P<0.001)$ with trans-11, cis-13 CLA (adjusted $\mathrm{R}^{2}=0.67$ ). Increases in the flow of cis-11 20:1, cis-11,cis-14 20:2, trans10,trans-14,trans- $17 \quad 20: 3, \quad$ cis-8, cis-11,cis-14,cis- 17 20:4, 20:5n-3, cis-11 22:1, cis-10,trans-14,cis-19 22:3, trans-8,cis-13,cis-16,cis-19 22:4, and cis-10,cis-13,cis16,cis-19 22:4 at the omasum were also associated $(P$ $<0.01$ ) with a decrease in milk fat yield (adjusted $\mathrm{R}^{2}$ $=0.55,0.61,0.63,0.56,0.64,0.57,0.54,0.55$, and 0.54 , respectively).

For all cows, a close relationship existed between the output in milk and the flow trans-10 18:1 at the omasum (secretion in milk, $\mathrm{g} / \mathrm{d}=0.34 \pm 0.031 \times$ flow at the omasum, $\mathrm{g} / \mathrm{d}+2.99 \pm 0.849 ; \mathrm{n}=15$, adjusted $\left.\mathrm{R}^{2}=0.89, P<0.001\right)$. A similar relationship also existed for trans-11 18:1 (secretion in milk, $\mathrm{g} / \mathrm{d}=0.46 \pm$ $0.104 \times$ flow at omasum, $\mathrm{g} / \mathrm{d}+4.84 \pm 5.682 ; \mathrm{n}=15$, adjusted $\left.\mathrm{R}^{2}=0.58, P<0.001\right)$. 


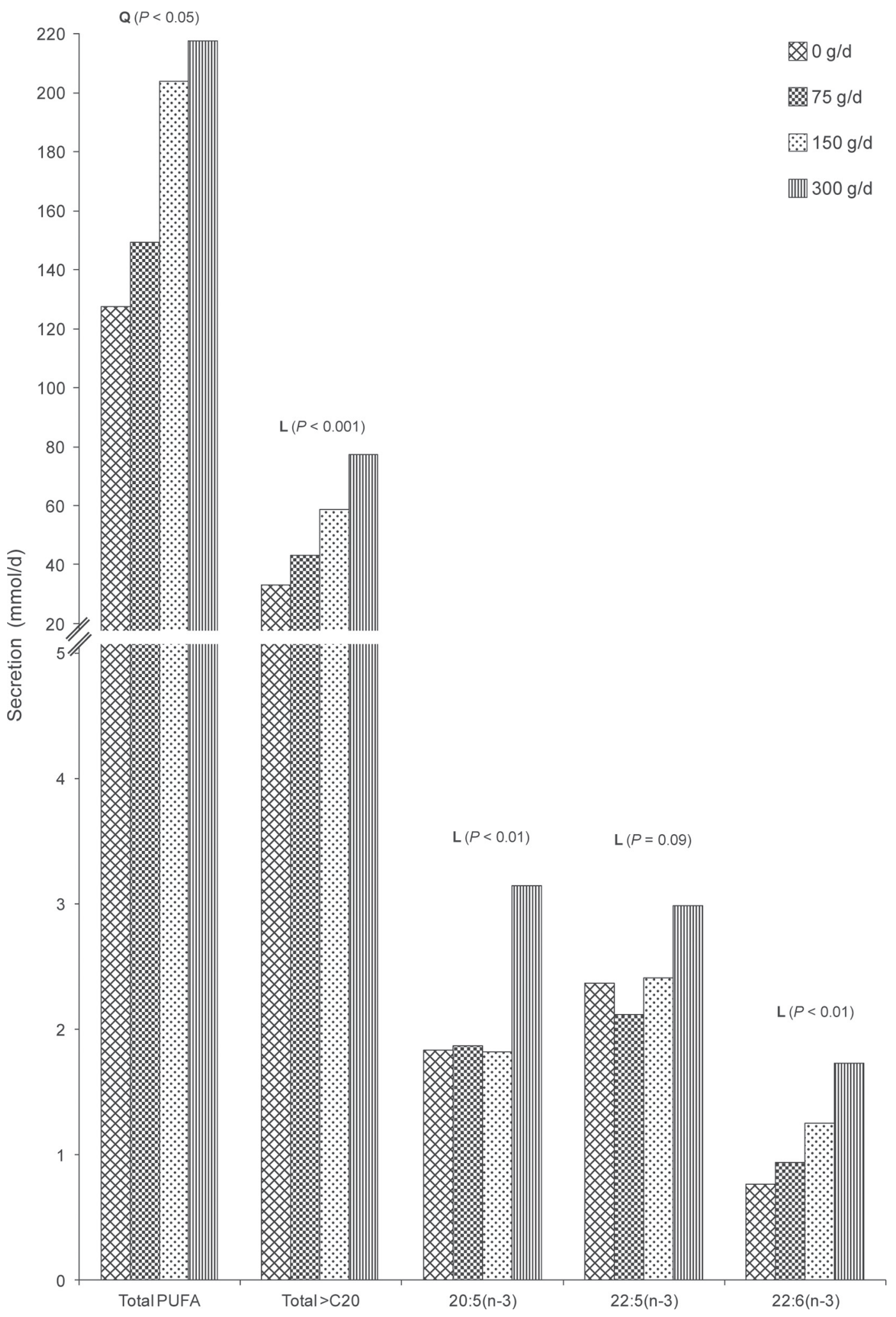

Figure 4. Effect of dietary fish oil supplements on the secretion of total polyunsaturated and selected long-chain FA in milk of lactating cows fed grass silage-based diets. L and Q indicate linear and quadratic components of the response to treatments, respectively. 
Based on measurements made for individual cows (n $=16)$ a close association existed between the intake $(\mathrm{x}, \mathrm{g} / \mathrm{d})$ and secretion in milk $(\mathrm{y}, \mathrm{g} / \mathrm{d})$ for $20: 5 \mathrm{n}-3(\mathrm{y}=$ $0.013 \pm 0.0034 \mathrm{x}+0.378 \pm 0.0787$; adjusted $\mathrm{R}^{2}=0.53$, $P=0.001), 22: 5 \mathrm{n}-3(\mathrm{y}=0.081 \pm 0.0332 \mathrm{x}+0.636 \pm$ 0.0865 ; adjusted $\left.\mathrm{R}^{2}=0.26, P=0.03\right)$, and $22: 6 \mathrm{n}-3(\mathrm{y}=$ $0.018 \pm 0.003 \mathrm{x}+0.123 \pm 0.051 ;$ adjusted $\mathrm{R}^{2}=0.68, P$ $<0.001)$. Similarly, a close association existed between the flow at the omasum $(\mathrm{x}, \mathrm{g} / \mathrm{d})$ and secretion in milk $(\mathrm{y}, \mathrm{g} / \mathrm{d})$ for $20: 5 \mathrm{n}-3(\mathrm{y}=0.128 \pm 0.0473 \mathrm{x}+0.447 \pm$ 0.0900 ; adjusted $\left.\mathrm{R}^{2}=0.31, P=0.02\right), 22: 5 \mathrm{n}-3(\mathrm{y}=$ $0.217 \pm 0.0436 \mathrm{x}+0.657 \pm 0.0490$; adjusted $\mathrm{R}^{2}=0.63$, $P<0.001)$, and $22: 6 \mathrm{n}-3(\mathrm{y}=0.170 \pm 0.0352 \mathrm{x}+0.167$ \pm 0.0510 ; adjusted $\left.\mathrm{R}^{2}=0.62, P<0.001\right)$.

\section{Association Between Milk Fat Yield And Milk FA Composition}

The loading plots for correlations between milk FA composition and milk fat content and yield based on the PLS analysis for the first 2 factors are shown in Supplemental Figures S1A-E (http://dx.doi. org/10.3168/jds.2015-9548) for all identified FA in milk fat, the sum of FA based on carbon chain length and degree of unsaturation, and 18-, and 20- to 22-isomers, respectively. The correlations with the first 2 factors are plotted along the horizontal and vertical axes, and the percentage of variation accounted for by each factor is indicated on the axis labels. Specific FA are predictor variables in the correlation loading plot with milk fat yield (Fatyd) and milk fat content (Fat) as response variables. The counter curves proportionately represent $1.0,0.75,0.50$, and 0.25 of the explained variation in each predictor and response variable that are accounted for by both factors. The location of a variable along the $\mathrm{x}$ - and $\mathrm{y}$-axes (distance from the origin on the graph) indicates the correlation of a variable with each of the 2 factors.

The first 2 factors accounted proportionately for 0.85 of total variance in response variables when all identified FA were included in the model (Supplemental Figures S1A and S1B; http://dx.doi.org/10.3168/ jds.2015-9548). Based on all available data, changes in the concentration of 160 individual FA in milk were associated with altered milk fat content and yield. Factor 1 discriminated milk fat content and yield, short-, and medium-chain SFA (4:0 to 14:0 and 16:0; positive loadings), and 16-, 18-, 20-, and 22-carbon unsaturated FA (negative loadings). Factor 2 discriminated 4:0 to 14:0 and 16:0 (north-east quadrant) from other FA including 18:0 and cis-9 18:1 in the south-east quadrant, trans-18:1 ( $\Delta 4-13)$, cis-11 18:1, trans-10, cis-12 CLA, $21: 5 n-3,22: 5 n-3$, and 22:6n-3 in the north-west quadrant, and cis-16:1 ( $\Delta 9$ and 12$)$, trans-16:1 ( $\Delta 11-13)$, trans-15 18:1, 18:3n-3, and trans-20:1 $(\Delta 9-13)$ in the south-west quadrant.

When combined, the correlation loading plots of all identified FA (Supplemental Figures S1A and S1B; http://dx.doi.org/10.3168/jds.2015-9548), total FA (Supplemental Figure S1C), 18-carbon FA (Supplemental Figure S1D), and 20- to 22-carbon FA (Supplemental Figure S1E), providing further information on the 2 discriminatory factors. Concentrations of PUFA, including long-chain n-3 FA and n-6 FA, were in most cases clustered in the north-west and south-west quadrants.

\section{DISCUSSION}

Several studies have examined milk fat 20:5n-3 and 22:6n-3 responses to dietary FO supplements in cows offered a range of diets (Offer et al., 1999; Donovan et al., 2000; Rego et al., 2005), but the possible benefits to human health need to be considered in the context of the overall changes in milk FA to FO. Changes in the distribution of 18-carbon FA in milk of cows fed FO have been reported (Shingfield et al., 2003; Loor et al., 2005), but much less information exists on the abundance of trans polyenoic FA. Furthermore, earlier reports have relied on the same elution order and isomer composition of partially hydrogenated plant oils to identify changes in milk trans 18:2 isomers to FO (Shingfield et al., 2003; Loor et al., 2005). A combination of preparative $\mathrm{Ag}^{+}$-TLC of FAME and GC-MS analysis of FAME and corresponding DMOX derivatives was used to analyze milk fat composition to avoid these uncertainties.

Appearance of unusual long-chain FA in milk from cows fed FO were initially identified based on GC-MS analysis of FAME. Molecular ions at $m / z 324,322,320$, $318,316,338,332,330,352,350,348,346,344$, and 342 , confirmed the appearance of $20: 1,20: 2,20: 3,20: 4$, $20: 5,21: 1,21: 4,21: 5,22: 1,22: 2,22: 3,22: 4,22: 5$, and 22:6 methyl esters, respectively, but the mass spectrum did not contain sufficient characteristic ion fragments to locate the position of one or more double bonds. Double bonds in long-chain unsaturated FA were located based on GC-MS analysis of DMOX derivatives. By cross-referencing peaks in the total ion chromatogram of DMOX derivatives with the relative retention time and elution order of methyl esters in the GC-FID chromatogram, minor FA in milk were able to be identified. In total, $174 \mathrm{FA}$ were able to identified in milk from cows fed FO. Of these, fifty-six 20-, 21-, or 22-carbon intermediates containing at least a single trans double bond and several all cis long-chain unsaturated FA were found to be increased in milk from cows fed FO. No conjugated 20-, 21-, and 22-carbon FA were detected in milk, consistent with an absence of these intermedi- 
ates in omasal digesta of experimental cows fed FO (Kairenius et al., 2011; Shingfield et al., 2012). A close relationship between flow at the omasum (Shingfield et al., 2012) and output in milk (Supplemental Table S3; http://dx.doi.org/10.3168/jds.2015-9548) suggests that most, if not all, of the unusual minor 20- to 22-carbon FA in milk from cows fed FO originated from the rumen rather than elongation of FA in nonmammary tissues or possible endogenous synthesis in the mammary gland.

\section{Milk Production and Composition}

In high amounts, FO decreased milk yield and lowered DMI without altering ruminal or total-tract OM digestibility (Shingfield et al., 2012). Earlier reports have also shown that dietary FO supplements often lowers milk yield, with the decrease being dependent on the amount (Donovan et al., 2000; Rego et al., 2005) and source of FO (Keady et al., 2000). Decreases in DMI and milk yield to lipid supplements have often been attributed to the adverse effects of unsaturated FA on the growth of specific populations of rumen cellulolytic bacteria (Jenkins, 1993). Comparisons of response to ruminal or abomasal infusion of FO indicate that the decreases in DMI are related to the effects of FA in FO on both ruminal digestion and metabolic effects, with the effects on rumen function being more important (Loor et al., 2005). The FO300 treatment lowered milk protein yield, whereas the FO150 treatment depressed milk protein content. Earlier studies have also reported that dietary FO supplements often lower milk protein output or milk protein concentrations (Offer et al., 1999; Donovan et al., 2000; Keady et al., 2000). In the present experiment, FO300 tended to lower milk lactose secretion, whereas earlier studies have reported that FO has no effect (Offer et al., 1999; Loor et al., 2005), decreases (Donovan et al., 2000), or increases (Keady et al., 2000) milk lactose output.

Increases in FO supplementation progressively decreased milk fat content and yield, which represents a typical response in lactating cows (Donovan et al., 2000; Keady et al., 2000; Rego et al., 2005). Even though FO is known to induce MFD, a direct cause and effect has not been established. Several theories have been proposed to explain diet induced MFD, the most recent being the biohydrogenation theory of MFD (Bauman and Griinari, 2001, 2003) which attributes the decrease in milk fat to changes in ruminal lipid metabolism leading to increased formation of specific biohydrogenation intermediates that inhibit milk fat synthesis. Trans-10,cis-12 CLA is the only intermediate shown unequivocally to inhibit milk fat synthesis (Baumgard et al., 2000), with some evidence that cis- 10,trans-12 CLA (Saebø et al., 2005) and trans-9,cis-11 CLA (Perfield et al., 2007) may also lower milk fat yield in lactating cows. In the present study, decreases in milk fat output to FO were not associated with increases in milk trans-10,cis-12 CLA or the amounts of trans9,cis-11 CLA and trans-10,cis-12 CLA at the omasum (Shingfield et al., 2012). No cis-10,trans-12 CLA was detected in omasal digesta (Shingfield et al., 2012) or in milk. An earlier study in lactating cows (Shingfield et al., 2003) also reported that FO does not increase the outflow of trans-10,cis-12 CLA from the rumen, with the implication that other biohydrogenation intermediates or mechanisms contribute to FO-induced MFD.

Increases in milk trans-10 18:1 content is a consistent feature of diet-induced MFD in lactating cows (Bauman and Griinari, 2003; Shingfield and Griinari, 2007). Increases in FO supplementation were associated with an increase in trans-10 18:1 at the omasum from 4.3 to $56.4 \mathrm{~g} / \mathrm{d}$ (Shingfield et al., 2012) and elevated trans-10 18:1 concentrations in milk fat from 0.34 to $4.20 \mathrm{~g} / 100$ $\mathrm{g}$ of FA, with the greatest increase to FO300. Reports on the physiological effects of trans-10 18:1 in the lactating cow are inconsistent. Abomasal infusion of 42.6 $\mathrm{g}$ of trans-10 18:1/d was shown to have no influence on milk fat secretion (Lock et al., 2007), findings that have been challenged on the basis that the enrichment of trans-10 18:1 in milk during postruminal infusions was too low for possible effects on mammary lipogenesis to be detected (Kadegowda et al., 2008). Further investigations have demonstrated that postruminal infusion of a mixture of 18:1 methyl esters supplying $92.1 \mathrm{~g} / \mathrm{d}$ of trans-10 18:1 over a 5-d period resulted in an approximate 20\% decrease in milk fat output (Shingfield et al., 2009). Even though a direct cause and effect could not be established, comparisons with reports in the literature and the relative abundance of constituents in the methyl ester preparation infused implicated trans-10 18:1 as the isomer responsible. Incubations of mammary epithelial cells with trans-10 18:1 have been shown to induce changes in lipogenic gene expression characterized as a downregulation of FASN, SCD, and SREBF1 (Kadegowda et al., 2009), suggesting that trans-10 18:1 may be active in the mammary gland. Across all treatments, a close negative association existed between trans-10 18:1 at the omasum and milk fat secretion, which may be considered evidence that increased formation of this biohydrogenation intermediate contributes to FO-induced MFD in lactating cows.

Decreases in milk fat secretion to increases in FO supplements were also associated with an increase in milk fat cis-11 18:1 concentration consistent with a negative relationship between these parameters reported previously for cows experiencing FO-induced MFD (Gama et al., 2008). Whereas cis-11 18:1 is a compo- 
nent of bacterial lipid and can be synthesized from the elongation of cis-9 16:1, the enrichment in milk on FO treatments can be explained by an increase in cis-11 18:1 at the omasum (Shingfield et al., 2012). Earlier experiments established that FO promotes ruminal escape of nonesterified cis-11 18:1 (Shingfield et al., 2003; Kairenius et al., 2011). Evidence on the biological activity of cis-11 18:1 in ruminants is equivocal. Postruminal infusion of a mixture of 18:1 isomers supplying up $12.4 \mathrm{~g} / \mathrm{d}$ of cis-11 18:1 in cows increased concentrations of this isomer in milk from 0.59 to $1.50 \mathrm{~g} / 100 \mathrm{~g}$ of FA with no changes in milk fat yield (Shingfield et al., 2007). However, recent investigations demonstrated that cis-11 18:1 lowered lipogenesis and FASN expression during incubation with bovine adipocytes (Burns et al., 2012).

During FO-induced MFD, decreases in milk fat synthesis are accompanied by lowered proportions of 18:0 and cis-9 18:1 in milk fat and higher trans-18:1 concentrations (Offer et al., 1999; Donovan et al., 2000; Rego et al., 2005). Milk fat triacylglycerol synthesis has a stringent requirement for cis-9 18:1 synthesized from 18:0 for the maintenance of milk fat fluidity and efficient ejection of fat from the mammary glands (Timmen and Patton, 1988). It has been suggested that decreases in the availability of 18:0 combined with an increase in trans 18:1 isomers that are not substrates for SCD may also contribute to FO induced MFD (Loor et al., 2005; Shingfield and Griinari, 2007; Gama et al., 2008). The melting point of trans FA is higher than cis FA, with the corollary that increases in the incorporation of trans 18:1 and lower amounts of cis-9 18:1 for milk fat triacylglycerol synthesis, without substantial changes in the availability of other FA substrates, may result in the melting point of milk fat globules exceeding body temperature. Direct evidence is limited, with a single experiment suggesting that an increase in milk fat melting point above $40^{\circ} \mathrm{C}$ as a factor regulating milk fat synthesis in cows fed FO (Gama et al., 2008). In the present experiment, FO had no effect on calculated mean milk fat melting point, despite of the substantial changes in milk FA composition. These observations are in broad agreement with a recent meta-analysis that concluded that variations in milk fat melting point in response to a wide range of dietary lipid supplements were much smaller than the variation in milk FA composition, a finding interpreted to indicate that the maintenance of milk fat melting point within a normal physiological range has a role in the regulation of milk fat synthesis during diet-induced MFD (Toral et al., 2013).

Based on the relationship between milk FA composition and milk fat yield, it has been suggested that trans-7 18:1 formed in the rumen, and the correspond- ing $S C D$ product, trans-7,cis-9 CLA synthesized in the mammary gland, may inhibit milk fat synthesis (Kadegowda et al., 2009). In the present study, no trans7,cis-9 CLA was detected in omasal digesta (Shingfield et al., 2012), increases in unresolved trans-6 to -8 18:1 at the omasum to FO were not associated with changes in milk fat yield (adjusted $\mathrm{R}^{2} \leq 0.05 ; P>0.05$ ), and no clear relationship existed between milk fat content or yield with milk trans-7, cis-9 CLA concentration (adjusted $\left.\mathrm{R}^{2} \leq 0.04 ; P>0.05\right)$.

In the loading plots for correlations between milk FA composition and milk fat content and yield, several close negative associations were identified between milk fat secretion and concentrations of trans-10 18:1 and several long-chain 16-, 18-, 20-, and 22-carbon PUFA containing one or more trans double bonds. Cows fed FO and experiencing MFD produced milk containing higher concentrations of FA containing a trans double bond or a hydroxy or oxo group located on carbons 9 and 10 relative to the carboxyl group that included trans-10 16:1, trans-10,trans-14 16:2, trans-10 18:1, unresolved trans-10,cis-15 18:2 and trans-11,cis-15 18:2, trans-10,trans-12 CLA, trans-10,cis-12 CLA, trans10,trans-14,trans-17 20:3, 10-OH-18:0, and 10-O-18:0. Furthermore, trans-8,trans-10 CLA, unresolved trans-9 and -10 20:1, and trans-10,trans-16 20:2 were located close to trans-10 18:1, but vertically opposite in the correlation loading plot. Overall, the PLS analysis suggested that FO-induced MFD may arise from changes in the availability of multiple FA, including decreases in 18:0 and the incorporation of cis-9 18:1 into milk fat triacylglycerol and increases in the abundance of trans-10 18:1 and mono and polyenoic trans 20- and 22-carbon intermediates.

\section{Milk FA Composition}

Supplements of FO progressively decreased the relative proportions of 4- to 16-carbon FA in milk that were accompanied by an increase in 14:0 and 16:0 at the omasum (Shingfield et al., 2012), which can be explained by the inhibitory effects of increases in longchain FA availability on $A C A C A$ activity and FA synthesis de novo in mammary secretory cells (Chilliard et al., 2001). Earlier studies have shown that FO results in a dose dependent decreases in the proportions of FA synthesized de novo (Donovan et al., 2000; Keady et al., 2000; Rego et al., 2005) and lowers mammary mRNA abundance for $A C A C A$ and $F A S N$ in lactating cows (Ahnadi et al., 2002). Decreased 18:0 and cis-18:1 concentrations is a consistent feature of changes in milk fat composition to FO supplements (Offer et al., 1999; Donovan et al., 2000; Rego et al., 2005), due to lowered availability of 18:0 for direct incorporation in milk fat 
or for endogenous synthesis of cis-9 18:1 in the mammary gland.

Dietary FO supplements progressively increased the milk cis-9 18:1:18:0 concentration ratio, without substantial changes in cis-9 18:1 at the omasum (Shingfield et al., 2012). Even though no measurements of $S C D$ gene or protein expression were made, the absence of treatment effects on milk fat cis-9 14:1:14:0 concentration ratios, that serve as a proxy of $S C D$ activity (Bernard et al., 2008), could be considered as evidence that the alterations in the cis-9 18:1:18:0 ratio may potentially arise from changes in $S C D$ substrate specificity. Reports of FO having a direct effect on $S C D$ transcription are equivocal. Dietary supplements of FO and soybean oil have been reported to decrease (Harvatine and Bauman, 2006) or increase (Invernizzi et al., 2010) mRNA abundance for $S C D 1$ in mammary tissue. When added to the diet or fed in rumen protected form, FO tended to decrease mammary $S C D$ mRNA abundance (Ahnadi et al., 2002), whereas $S C D 1$ transcription was recently demonstrated to be unaffected by abomasal infusion of FO (Dallaire et al., 2014).

Fish oil increased milk trans FA concentrations several-fold, which can be attributed to the incomplete biohydrogenation of unsaturated 16- to 22- carbon FA in the rumen (Shingfield et al., 2012). Studies in vitro have demonstrated that both 20:5n-3 and 22:6n-3 inhibit the reduction of 18-carbon unsaturated FA to 18:0 causing trans 18:1 and trans 18:2 intermediates to accumulate (AbuGhazaleh and Jenkins, 2004; Klein and Jenkins, 2011).

Increases in milk trans 16-carbon FA concentrations were isomer-dependent and due in the most part to trans-9, -11, and -12 16:1 enrichment. Few investigations have examined the fate of 16-carbon unsaturated FA in the rumen or the distribution of 16-carbon intermediates in milk (Destaillats et al., 2000), but the increase in 16:1 isomers at the omasum in cows fed FO has been attributed to incomplete ruminal metabolism of 16:2n-4, 16:3n-4, 16:4n-1, and 16:4n-3 (Shingfield et al., 2012).

The majority of the increase in total milk trans FA content to FO was associated with specific enrichment of trans 18:1 $(\Delta 8-12)$ and trans $18: 2(\Delta 9,11 ; \Delta 9,12$; $\Delta 11,15)$ isomers. Earlier studies have also reported that FO increases the concentration of trans 18:1 and trans 18:2 intermediates in milk (Shingfield et al., 2003; Loor et al., 2005). Complementary Ag+-TLC fractionation of FAME and GC-MS analysis of DMOX derivatives indicated that FO results in the appearance of 21 minor 18:2 isomers in milk not reported previously.

Decreases in milk fat content and secretion were associated with increases in milk fat concentration of unresolved trans-10,cis-15 18:2 and trans-11,cis-15 18:2.
Even though separation using the CP-Sil 88 capillary column was not possible, further work in our laboratory based on GC-MS and GC-FID analysis with the 100-m SLB-IL111 capillary column (Alves and Bessa, 2014) has allowed trans-10,cis-15 18:2 to be isolated in milk fat and omasal digesta of cows fed $200 \mathrm{~g}$ of FO/d (P. Kairenius, unpublished data). Revisiting the analysis of 18:2 isomers in omasal digesta of experimental cows revealed that trans-10,cis-15 18:2 was erroneously reported to coelute with trans-9, cis- 12 18:2, cis-12,trans-16 18:2, and cis-8,cis-12 18:2 (Shingfield et al., 2012). Increases in ruminal formation of trans-10,cis-15 18:2 and incorporation in milk provides further evidence that FO alters the biohydrogenation of 18-carbon PUFA. Earlier studies have demonstrated that increases in trans-11,cis-15 18:2 in milk are not accompanied with MFD (Roy et al., 2006; Benchaar et al., 2012), suggesting that trans-10,cis-15 18:2 may contribute to FO-induced MFD.

Consistent with earlier reports, FO increased milk cis-9,trans-11 CLA content (Offer et al., 1999; Donovan et al., 2000; Shingfield et al., 2003), which can be explained by an increase in the supply of trans-11 18:1 (Shingfield et al., 2012) for endogenous cis-9,trans-11 CLA synthesis in the mammary gland (Griinari et al., 2000). Enrichment of cis-9,trans-11 CLA concentrations were highest on the FO150 treatment and not increased further, due to alterations in ruminal biohydrogenation on FO300 causing trans-10 18:1 to accumulate with no change in trans-11 18:1 leaving the rumen (Shingfield et al., 2012).

Trans-7, cis-9 CLA was not detected in omasal digesta (Shingfield et al., 2012) but increased in milk reaching a maximum on FO150, which can be explained by greater amounts of trans-7 18:1 at the omasum (Shingfield et al., 2012) being used for endogenous synthesis of trans7,cis-9 CLA in the mammary gland (Corl et al., 2002). Secretion of cis-9,trans-12 18:2, cis-9,trans-13 18:2, and cis-9,trans-14 18:2 in milk also exceeded the flow at the omasum, providing further evidence that these isomers are formed via the action of $S C D$ on trans-12 to -14 18:1 in the bovine mammary gland (Griinari et al., 2000; Shingfield et al., 2008).

Supplements of FO elevated milk 20:5n-3, 22:5n-3, and 22:6n-3 concentrations in a dose-dependent manner, increases that were associated with a mean apparent transfer efficiency of 20:5n-3, 22:5n-3, and 22:6n-3 from the diet into milk of $1.3,8.1$, and $1.8 \%$, respectively; this is consistent with values of between 0.5 and $5.7 \%$ for $20: 5 n-3$ and $22: 6 n-3$ and 6.1 to $20.3 \%$ for $22: 5 n-3$ reported in the literature (Lock and Bauman, 2004; Rego et al., 2005; Palmquist, 2009). The rather low apparent transfer of 20:5n-3 and 22:6n-3 from the diet into milk of lactating reflects extensive biohydrogenation of 
these FA in the rumen (Shingfield et al., 2003; Loor et al., 2005; Shingfield et al., 2012); following absorption these FA are incorporated into cholesterol esters and phospholipids that have a low affinity for lipoprotein lipase in the mammary endothelium (Offer et al., 1999). A higher efficiency of transfer for 22:5n-3 compared with 20:5n-3 or 22:6n-3, is more apparent than true due to potential elongation of $20: 5 n-3$ to $22: 5 n-3$ and retroconversion of 22:6n-3 to $22: 5 \mathrm{n}-3$ in body tissues (Palmquist, 2009).

Numerous long-chain intermediates formed during biohydrogenation of FA in FO were found to be absorbed and incorporated into milk triacylglycerols. Fish oil resulted in dose-dependent increases in 20- and 22-carbon trans FA concentrations (range 0.16-1.61 and $0.01-0.28 \mathrm{~g} / 100 \mathrm{~g}$ of $\mathrm{FA}$, respectively), with trans 20:1, 20:2, and 20:3 isomers being the most abundant $(0.18,0.27$, and $0.17 \mathrm{~g} / 100 \mathrm{~g}$ of FA, respectively). However, the implications of increases in long-chain trans mono- and polyenoic FA in milk from cows fed FO on the health of consumers remains unclear.

\section{CONCLUSIONS}

In cows fed grass silage-based diets, FO supplements lowered DMI, the yields of ECM, milk fat, protein, and milk fat content in a dose-dependent manner. Decreases in milk fat synthesis were not associated with higher incorporation of trans-10,cis-12 CLA in milk fat or changes in estimated milk fat melting point. Partial least square regression suggested that lowered 18:0 availability along with higher mammary uptake of cis-11 18:1, trans-10 18:1, and trans 20- and 22-carbon intermediates originating from the rumen may contribute directly or indirectly to FO-induced MFD. Increasing amounts of FO progressively enriched 20:5n-3 and 22:6n-3 in milk, changes that were accompanied by dosedependent decreases in 4- to 18-carbon saturated FA, and several-fold increases in CLA, trans FA, and PUFA concentrations. Fish oil also resulted in the appearance of 37 unique 20- and 22-carbon FA in milk fat. Even though dietary FO supplements can be used to enrich 20:5n-3 and 22:6n-3 in milk from cows several-fold, the associated changes in the abundance and distribution of FA containing a single or several trans double bonds on human health merits further investigation.

\section{ACKNOWLEDGMENTS}

The authors gratefully acknowledge the contribution of staff under the supervision of Aino Matilainen at the Animal Metabolism Unit of MTT Agrifood Research Finland (Jokioinen; Natural Resources Institute Finland since 2015) for care of experimental animals and assistance during sample collection. Valued contributions of Minna Aalto and Mervi Mikkola (MTT Agrifood Research Finland) to sample lipid analysis are appreciated. The provision of ultrarefined herring and mackerel oil by Pronova Biocare AS (Aalesund, Norway) and financial support from the Finnish Ministry of Agriculture and Forestry (Helsinki, Finland) is gratefully acknowledged.

\section{REFERENCES}

AbuGhazaleh, A. A., and T. C. Jenkins. 2004. Disappearance of docosahexaenoic and eicosapentaenoic acids from cultures of mixed ruminal microorganisms. J. Dairy Sci. 87:645-651.

Ahnadi, C. E., N. Beswick, L. Delbecchi, J. J. Kennelly, and P. Lacasse. 2002. Addition of fish oil to diets for dairy cows. II. Effects on milk fat and gene expression of mammary lipogenic enzymes. J. Dairy Res. 69:521-531.

Alves, S. P., and R. J. Bessa. 2014. The trans-10,cis-15 18:2: A missing intermediate of trans-10 shifted rumen biohydrogenation pathway? Lipids 49:527-541.

Bauman, D. E., and J. M. Griinari. 2001. Regulation and nutritional manipulation of milk fat: Low-fat milk syndrome. Livest. Prod. Sci. 70:15-29.

Bauman, D. E., and J. M. Griinari. 2003. Nutritional regulation of milk fat synthesis. Annu. Rev. Nutr. 23:203-227.

Baumgard, L. H., B. A. Corl, D. A. Dwyer, A. Sæbø, and D. E. Bauman. 2000. Identification of the conjugated linoleic acid isomer that inhibits milk fat synthesis. Am. J. Physiol. Regul. Integr. Comp. Physiol. 278:R179-R184.

Benchaar, C., G. A. Romero-Pérez, P. Y. Chouinard, F. Hassanat, M. Eugene, H. V. Petit, and C. Côrtes. 2012. Supplementation of increasing amounts of linseed oil to dairy cows fed total mixed rations: effects on digestion, ruminal fermentation characteristics, protozoal populations, and milk fatty acid composition. J. Dairy Sci. 95:4578-4590.

Bernard, L., C. Leroux, and Y. Chilliard. 2008. Expression and nutritional regulation of lipogenic genes in the ruminant lactating mammary gland. Adv. Exp. Med. Biol. 606:67-108.

Burns, T. A., A. K. G. Kadegowda, S. K. Duckett, S. L. Pratt, and T. C. Jenkins. 2012. Palmitoleic (16:1 cis-9) and cis-vaccenic (18:1 cis-11) acid alter lipogenesis in bovine adipocyte cultures. Lipids 47:1143-1153.

Chilliard, Y., A. Ferlay, and M. Doreau. 2001. Effect of different types of forages, animal fat or marine oils in cow's diet on milk fat secretion and composition, especially conjugated linoleic acid (CLA) and polyunsaturated fatty acids. Livest. Prod. Sci. 70:31-48.

Corl, B. A., L. H. Baumgard, J. M. Griinari, P. Delmonte, K. M. Morehouse, M. P. Yurawecz, and D. E. Bauman. 2002. Trans7,cis-9 CLA is synthesized endogenously by delta9-desaturase in dairy cows. Lipids 37:681-688.

Dallaire, M. P., H. Taga, L. Ma, B. A. Corl, R. Gervais, Y. Lebeuf, F. J. Richard, and P. Y. Chouinard. 2014. Effects of abomasal infusion of conjugated linoleic acids, Sterculia foetida oil, and fish oil on production performance and the extent of fatty acid $\Delta^{9}$ desaturation in dairy cows. J. Dairy Sci. 97:6411-6425.

Destaillats, F., R. L. Wolff, D. Precht, and J. Molkentin. 2000. Study of individual trans- and cis-16:1 isomers in cow, goat, and ewe cheese fats by gas-liquid chromatography with emphasis on the trans- $\Delta 3$ isomer. Lipids 35:1027-1032.

Donovan, D. C., D. J. Schingoethe, R. J. Baer, J. Ryali, A. R. Hippen, and S. T. Franklin. 2000. Influence of dietary fish oil on conjugated linoleic acid and other fatty acids in milk fat from lactating dairy cows. J. Dairy Sci. 83:2620-2628.

Gama, M. A. S., P. C. Garnsworthy, J. M. Griinari, P. R. Leme, P. H. M. Rodrigues, L. W. O. Souza, and D. P. D. Lanna. 2008. Dietinduced milk fat depression: Association with changes in milk fatty acid composition and fluidity of milk fat. Livest. Sci. 115:319-331. 
Griinari, J. M., B. A. Corl, S. H. Lacy, P. Y. Chouinard, K. V. Nurmela, and D. E. Bauman. 2000. Conjugated linoleic acid is synthesized endogenously in lactating dairy cows by $\Delta 9$-desaturase. $\mathrm{J}$. Nutr. 130:2285-2291.

Gunstone, F. D., J. L. Harwood, and F. B. Padley. 1994. The Lipid Handbook. 2nd ed. Chapman and Hall, New York, NY.

Halmemies-Beauchet-Filleau, A., T. Kokkonen, A.-M. Lampi, V. Toivonen, K. J. Shingfield, and A. Vanhatalo. 2011. Effect of plant oils and camelina expeller on milk fatty acid composition in lactating cows fed diets based on red clover silage. J. Dairy Sci. 94:4413-4430.

Harvatine, K. J., and D. E. Bauman. 2006. SREBP1 and thyroid hormone responsive spot 14 (S14) are involved in the regulation of bovine mammary lipid synthesis during diet-induced milk fat depression and treatment with CLA. J. Nutr. 136:2468-2474.

Invernizzi, G., B. J. Thering, M. A. McGuire, G. Savoini, and J. J. Loor. 2010. Sustained upregulation of stearoyl-CoA desaturase in bovine mammary tissue with contrasting changes in milk fat synthesis and lipogenic gene networks caused by lipid supplements. Funct. Integr. Genomics 10:561-575.

Jenkins, T. C. 1993. Lipid metabolism in the rumen. J. Dairy Sci. 76:3851-3863.

Jensen, R. G., and S. Patton. 2000. The effect of maternal diets on the mean melting points of human milk fatty acids. Lipids 35:11591161.

Kadegowda, A. K. G., M. Bionaz, L. S. Piperova, R. A. Erdman, and J. J. Loor. 2009. Peroxisome proliferator-activated receptor- $\gamma$ activation and long-chain fatty acids alter lipogenic gene networks in bovine mammary epithelial cells to various extents. J. Dairy Sci. 92:4276-4289.

Kadegowda, A. K. G., L. S. Piperova, and R. A. Erdman. 2008. Principal component and multivariate analysis of milk long-chain fatty acid composition during diet-induced milk fat depression. J. Dairy Sci. 91:749-759.

Kairenius, P., V. Toivonen, and K. J. Shingfield. 2011. Identification and ruminal outflow of long-chain fatty acid biohydrogenation intermediates in cows fed diets containing fish oil. Lipids 46:587-606.

Keady, T. W. J., C. S. Mayne, and D. A. Fitzpatrick. 2000. Effects of supplementation of dairy cattle with fish oil on silage intake, milk yield and milk composition. J. Dairy Res. 67:137-153.

Klein, C. M., and T. C. Jenkins. 2011. Docosahexaenoic acid elevates trans-18:1 isomers but is not directly converted into trans-18:1 isomers in ruminal batch cultures. J. Dairy Sci. 94:4676-4683.

Lock, A. L., and D. E. Bauman. 2004. Modifying milk fat composition of dairy cows to enhance fatty acids beneficial to human health. Lipids 39:1197-1206.

Lock, A. L., C. Tyburczy, D. A. Dwyer, K. J. Harvatine, F. Destaillats, Z. Mouloungui, L. Candy, and D. E. Bauman. 2007. Trans-10 octadecenoic acid does not reduce milk fat synthesis in dairy cows. J. Nutr. 137:71-76.

Loor, J. J., M. Doreau, J. M. Chardigny, A. Ollier, J. L. Sébédio, and Y. Chilliard. 2005. Effects of ruminal or duodenal supply of fish oil on milk fat secretion and profiles of trans-fatty acids and conjugated linoleic acid isomers in dairy cows fed maize silage. Anim. Feed Sci. Technol. 119:227-246.

Offer, N. W., M. Marsden, J. Dixon, B. K. Speakel, and F. E. Thacker. 1999. Effect of dietary fat supplements on levels of n-3 poly-unsaturated fatty acids, trans acids and conjugated linoleic acid in bovine milk. Anim. Sci. 69:613-625.

Palmquist, D. L. 2009. Omega-3 fatty acids in metabolism, health, and nutrition and for modified animal product foods. Prof. Anim. Sci. 25:207-249.

Perfield, J. W., A. L. Lock, J. M. Griinari, A. Sæbø, P. Delmonte, D. A. Dwyer, and D. E. Bauman. 2007. Trans-9, cis-11 conjugated linoleic acid reduces milk fat synthesis in lactating dairy cows. J. Dairy Sci. 90:2211-2218.

Rego, O. A., H. J. D. Rosa, P. Portugal, R. Cordeiro, A. E. S. Borba, C. M. Vouzela, and R. J. B. Bessa. 2005. Influence of dietary fish oil on conjugated linoleic acid, omega-3 and other fatty acids in milk fat from grazing dairy cows. Livest. Prod. Sci. 95:27-33.

Roy, A., A. Ferlay, K. J. Shingfield, and Y. Chilliard. 2006. Examination of the persistency of milk fatty acid composition responses to plant oils in cows given different basal diets, with particular emphasis on trans-C18:1 fatty acids and isomers of conjugated linoleic acid. Anim. Sci. 82:479-492.

Saeb $\varnothing$, A., P. Sæb $\varnothing$, J. M. Griinari, and K. J. Shingfield. 2005. Effect of abomasal infusion of geometric isomers of 10,12 conjugated linoleic acid on milk fat synthesis in dairy cows. Lipids 40:823-832.

Shingfield, K. J., V. Toivonen, A. Vanhatalo, P. Huhtanen, and J. M. Griinari. 2006. Short communication: Indigestible markers reduce the mammary 9-desaturase index and alter the milk fatty acid composition in cows. J. Dairy Sci. 89:3006-3010.

Shingfield, K. J., S. Ahvenjärvi, V. Toivonen, A. Ärölä, K. V. V. Nurmela, P. Huhtanen, and J. M. Griinari. 2003. Effect of dietary fish oil on biohydrogenation of fatty acids and milk fatty acid content in cows. Anim. Sci. 77:165-179.

Shingfield, K. J., S. Ahvenjärvi, V. Toivonen, A. Vanhatalo, and P. Huhtanen. 2007. Transfer of absorbed cis-9,trans-11 conjugated linoleic acid into milk is biologically more efficient than endogenous synthesis from absorbed vaccenic acid in lactating cows. J. Nutr. 137:1154-1160.

Shingfield, K. J., M. Bonnet, and N. D. Scollan. 2013. Recent developments in altering the fatty acid composition of ruminant-derived foods. Animal 7(Suppl. 1):132-162.

Shingfield, K. J., Y. Chilliard, V. Toivonen, P. Kairenius, and D. I. Givens. 2008. Trans fatty acids and bioactive lipids in ruminant milk. Pages 3-65 in Bioactive Components of Milk. Advances in Experimental Medicine and Biology. Z. Bösze, ed. Springer, New York, NY

Shingfield, K. J., and J. M. Griinari. 2007. Role of biohydrogenation intermediates in milk fat depression. Eur. J. Lipid Sci. Technol. 109:799-816.

Shingfield, K. J., P. Kairenius, A. Ärölä, D. Paillard, S. Muetzel, S. Ahvenjärvi, A. Vanhatalo, P. Huhtanen, V. Toivonen, J. M. Griinari, and R. J. Wallace. 2012. Dietary fish oil supplements modify ruminal biohydrogenation, alter the flow of fatty acids at the omasum, and induce changes in the ruminal Butyrivibrio population in lactating cows. J. Nutr. 142:1437-1448.

Shingfield, K. J., A. Sæbø, P.-C. Sæbø, V. Toivonen, and J. M. Griinari. 2009. Effect of abomasal infusions of a mixture of octadecenoic acids on milk fat synthesis in lactating cows. J. Dairy Sci. 92:4317-4329.

Sjauna, L. O., L. Baevre, L. Junkkarinen, J. Pedersen, and J. Setälä. 1990. A nordic proposal for an energy corrected milk (ECM) formular. 27th Session of ICRPMA, July 2-6, Paris, France.

Small, D. M. 1986. The physical chemistry of lipids: From alkanes to phospholipids. Pages 367-372 in Handbook of Lipid Research. Vol. 4. D. J. Hanahan, ed. Plenum Press, New York, NY.

Timmen, H., and S. Patton. 1988. Milk fat globules: Fatty acid composition, size and in vivo regulation of fat liquidity. Lipids 23:685689

Tobias, R. D. 1995. An Introduction to Partial Least Squares Regression. SUGI Proceedings. Accessed Feb. 28, 2015. http://support. sas.com/rnd/app/stat/papers/pls.pdf.

Toral, P. G., L. Bernard, Y. Chilliard, and F. Glasser. 2013. Short communication: Diet-induced variations in milk fatty acid composition have minor effects on the estimated melting point of milk fat in cows, goats, and ewes: Insights from a meta-analysis. J. Dairy Sci. 96:1232-1236.

Toral, P. G., K. J. Shingfield, G. Hervás, V. Toivonen, and P. Frutos. 2010. Effect of fish oil and sunflower oil on rumen fermentation characteristics and fatty acid composition of digesta in ewes fed a high concentrate diet. J. Dairy Sci. 93:4804-4817.

WHO. 2003. Diet, Nutrition and the Prevention of Chronic Diseases. Report of a Joint WHO/FAO Expert Consultation. WHO Technical Report Series no. 916. World Health Organization, Geneva, Switzerland. 